\title{
SINTERED S53P4 BIOACTIVE GLASS SCAFFOLDS HAVE ANTI-INFLAMMATORY PROPERTIES AND STIMULATE OSTEOGENESIS IN VITRO
}

\author{
R. Björkenheim ${ }^{1, *}$, E. Jämsen², E. Eriksson ${ }^{1}$, P. Uppstu ${ }^{3}$, L. Aalto-Setälä4, L. Hupa ${ }^{4}$, K.K. Eklund ${ }^{2,5}$, \\ M. Ainola ${ }^{2}$, N.C. Lindfors ${ }^{1}$ and J. Pajarinen ${ }^{1,6}$ \\ ${ }^{1}$ Department of Musculoskeletal and Plastic Surgery, University of Helsinki and \\ Helsinki University Hospital, Helsinki, Finland \\ ${ }^{2}$ Translational Immunology Research Program, Faculty of Medicine, University of Helsinki, \\ Helsinki, Finland \\ ${ }^{3}$ Polymer Technology Research Group, Faculty of Science and Engineering, \\ Åbo Akademi University, Turku, Finland \\ ${ }^{4}$ Johan Gadolin Process Chemistry Centre, Åbo Akademi University, Turku, Finland \\ ${ }^{5}$ Department of Rheumatology, Helsinki University and Helsinki University Hospital, and \\ Orton Orthopedic Hospital and Research Institute, Helsinki, Finland \\ ${ }^{6}$ Päijät-Häme central hospital, Department of Surgery, Lahti, Finland
}

\begin{abstract}
Bioactive glasses (BAG) are used as bone-graft substitutes in orthopaedic surgery. A specific BAG scaffold was developed by sintering BAG-S53P4 granules. It is hypothesised that this scaffold can be used as a bone substitute to fill bone defects and induce a bioactive membrane (IM) around the defect site. Beyond providing the scaffold increased mechanical strength, that the initial inflammatory reaction and subsequent IM formation can be enhanced by coating the scaffolds with poly(DL-lactide-co-glycolide) (PLGA) is also hypothesised. To study the immunomodulatory effects, BAG-S53P4 ( \pm PLGA) scaffolds were placed on monolayers of primary human macrophage cultures and the production of various pro- and anti-inflammatory cytokines was assessed using reverse transcriptase quantitative polymerase chain reaction (RT-qPCR) and ELISA. To study the osteogenic effects, BAG-S53P4 ( \pm PLGA) scaffolds were cultured with rabbit mesenchymal stem cells and osteogenic differentiation was evaluated by RT-qPCR and matrix mineralisation assays. The scaffold ion release was quantified and the BAG surface reactivity visualised. Furthermore, the $\mathrm{pH}$ of culture media was measured. BAG-S53P4 scaffolds had both anti-inflammatory and osteogenic properties that were likely attributable to alkalinisation of the media and ion release from the scaffold. $\mathrm{pH}$ change, ion release, and immunomodulatory properties of the scaffold could be modulated by the PLGA coating. Contrary to the hypothesis, the coating functioned by attenuating the BAG surface reactions and subsequent anti-inflammatory properties, rather than inducing an elevated inflammatory response compared to BAG-S53P4 alone. These results further validated the use of BAG-S53P4 ( \pm PLGA) scaffolds as bone substitutes and indicate that scaffold properties can be tailored to a specific clinical need.
\end{abstract}

Keywords: Bioactive glass, S53P4, PLGA, anti-inflammatory, osteogenesis stimulation.

*Address for correspondence: Robert Björkenheim, Department of Musculoskeletal and Plastic Surgery, University of Helsinki, Helsinki University Hospital, Topeliuksenkatu 5B, $3^{\text {rd }}$ floor, 00260 Helsinki, Finland. Telephone number: +35894711 Email: robert.bjorkenheim@hus.fi

Copyright policy: This article is distributed in accordance with Creative Commons Attribution Licence (http://creativecommons.org/licenses/by-sa/4.0/).

\section{List of Abbreviations}

ANOVA

AR

BAGs

$\mathrm{BM}$

BMP analysis of variance

alizarin red

bioactive glasses

basal MSC growth medium

bone morphogenetic protein
cDNA

EDX

ELISA

FMOD

GM-CSF complementary DNA electron-dispersive $\mathrm{X}$-ray analysis enzyme-linked-immunosorbent assays fibromodulin granulocyte macrophage colonystimulating factor 


\begin{tabular}{|c|c|}
\hline HA & hydroxyapatite \\
\hline h-PBMCs & $\begin{array}{l}\text { human peripheral blood } \\
\text { mononuclear cells }\end{array}$ \\
\hline HPRT1 & hypoxanthine \\
\hline ICP-OES & $\begin{array}{l}\text { phosphoribosyltransferase } 1 \\
\text { inductively-coupled-plasma- } \\
\text { optical-emission spectrometry }\end{array}$ \\
\hline IL-1Ra & interleukin-1 receptor antagonist \\
\hline IL-1 $\beta$ & interleukin $1 \beta$ \\
\hline IL-6 & interleukin 6 \\
\hline IM & induced membrane \\
\hline IMT & induced membrane technique \\
\hline LAL & Limulus amoebocyte lysate \\
\hline $\mathrm{LDH}$ & lactate dehydrogenase \\
\hline LPS & lipopolysaccharide \\
\hline mRNA & messenger ribonucleic acid \\
\hline MSC & mesenchymal stem cell \\
\hline OGN & osteoglycin \\
\hline $\mathrm{OM}$ & osteogenic differentiation medium \\
\hline PBS & phosphate-buffered saline \\
\hline PFA & paraformaldehyde \\
\hline PLGA & poly(DL-lactide-co-glycolide) \\
\hline qPCR & $\begin{array}{l}\text { quantitative polymerase chain } \\
\text { reaction }\end{array}$ \\
\hline Rb-MSCs & rabbit bone marrow-derived MSCs \\
\hline RPLP0 & $\begin{array}{l}\text { ribosomal protein lateral stalk } \\
\text { subunit P0 }\end{array}$ \\
\hline RT-qPCR & $\begin{array}{l}\text { reverse transcriptase quantitative } \\
\text { polymerase chain reaction }\end{array}$ \\
\hline RUNX2 & runt-related transcription factor 2 \\
\hline SEM & scanning electron microscopy \\
\hline SFM & serum-free medium \\
\hline TNF $\alpha$ & tumour necrosis factor $\alpha$ \\
\hline VEGF & vascular endothelial growth factor \\
\hline
\end{tabular}

\section{Introduction}

BAGs were first described by Hench and Paschall in the late 1960s (Hench and Paschall, 1973) and have since been a focus of increasing interest for biomedical applications. In particular, BAGs have emerged as effective bone graft substitutes that have both osteoconductive and osteostimulative properties (Hench et al., 2000; Hench et al., 2004; Wilson and Low, 1992; Xynos et al., 2000; Xynos et al., 2001). In the bone tissue microenvironment, a layer of HA is formed on the surface of the BAG that allows direct osteoconduction and formation of a strong mechanical bond between the material and bone. In addition, various dissolution products, such as $\mathrm{Si}$, $\mathrm{Ca}$, and $\mathrm{P}$ species released from silicate-based BAGs $\left(\mathrm{SiO}_{2}-\mathrm{CaO}-\mathrm{Na}_{2} \mathrm{O}-\mathrm{P}_{2} \mathrm{O}_{5}\right)$ have been shown to stimulate osteogenic gene expression in cells involved in bone healing (Hoppe et al., 2011).

BAG-S53P4 granules, a specific type of BAG, are widely used as a bone graft substitute for bone tumours, trauma, and spine surgery. Indeed, it has been stated that BAG-S53P4 is the most frequently used BAG in clinical practice (Baino et al., 2018; Jones, 2013). In addition to promoting bone regeneration,
BAG-S53P4 granules have antimicrobial properties that are based on the elevation of $\mathrm{pH}$ in the local microenvironment, due to the dissolution of the BAG (Stoor et al., 1998). Furthermore, the changes in osmotic pressure and ion concentrations have been reported to contribute to the antimicrobial properties (Leppäranta et al., 2008; Munukka et al., 2008; Zhang et al., 2010). Thus, BAG-S53P4 granules are also used in the treatment of severe chronic osteomyelitis, mastoiditis as well as spine and frontal sinus infections (Kankare and Lindfors, 2016; Lindfors et al., 2010a; Lindfors et al., 2009; Lindfors et al., 2010b; Stoor et al., 2010).

IMT (Masquelet et al., 2000) has emerged as an effective method for treating bone defects. At present, the IMT is a 2-staged procedure; first, a foreign body membrane is induced around the defect area by utilising a temporary spacer, followed by removal of the spacer and filling of the defect with a bone graft or corresponding substituent. The induced membrane, surrounding the defect and the bone graft, conveys ample vasculature. It also contains osteoprogenitor cells, and releases cytokines and growth factors (Gruber et al., 2016) - i.e. several factors of the diamond (Giannoudis et al., 2007) or hexagon (Loi et al., 2016) concept required for successful bone healing. The induced membrane also contains high concentrations of VEGF and other growth factors essential for inducing vascularisation and bone formation (Pelissier et al., 2004). The unique properties of the BAG, such as its osteoconductive, osteostimulative, and anti-microbial properties, would make the material ideal for the development of a 1-staged IMT. Indeed, an ongoing clinical trial (Tanner et al., 2018) is investigating the use of BAGS53P4 granules as the sole substitute in filling of segmental defects using the IMT.

A BAG-S53P4 scaffold was developed by sintering S53P4 granules. It was hypothesised that this scaffold could be used as the sole bone substitute to fill bone defects, with the additional ability of inducing a bioactive membrane around the bone defect site. Such an approach would convert the 2-stage IMT into a 1-stage technique, thus eliminating the need for additional surgery and potential complications related to the second procedure. Indeed, it has been shown, in an in vivo rabbit model, that sintered BAG-S53P4 scaffolds not only stimulate early bone formation within the scaffold, but also induce a bioactive membrane with ample microvasculature and upregulated VEGF and BMP expression (Björkenheim et al., 2017; Björkenheim et al., 2019). In addition to giving the sintered BAG scaffold increased mechanical strength (Mantsos et al., 2009; Shi et al., 2018), PLGA coating is hypothesised to induce a stronger initial inflammatory reaction than BAG-S53P4 alone, with enhanced induced membrane formation and bone regeneration (Björkenheim et al., 2017; Björkenheim et al., 2019; Nicolete et al., 2011). This concept of polymer coated BAG scaffolds is not new; one of the first BAG scaffolds with 
polymer coating was described by Chen et al. in 2006 (Chen and Boccaccini, 2006). Due to brittleness, the 45S5 scaffolds were coated with the polymer poly(D,L-lactic acid) to achieve enhanced mechanical properties (Chen and Boccaccini, 2006). Furthermore, BAG in combination with PLGA can evoke enhanced biological activities both in vitro and in vivo, compared to BAG alone (Magri et al., 2019).

The aim of this study was to characterise the various cell biological effects of BAG-S53P4 scaffolds and the effects of PLGA coating for use in a single-stage IMT (Masquelet, 2000). Both the immunomodulatory and osteogenic properties of the scaffolds in macrophage and MSC culture models, respectively, were assessed. The $\mathrm{pH}$ change and ions released by dissolving scaffolds were also assessed in order to understand the underlying cellular biological mechanisms.

\section{Materials and Methods}

\section{Production and coating of bioactive glass scaffolds}

BAG-S53P4 ( \pm PLGA) scaffolds were manufactured as previously described (Björkenheim et al., 2017; Björkenheim et al., 2019). Briefly, BAG-S53P4 (composition in $\mathrm{wt}^{\%}$ : $53 \% \mathrm{SiO}_{2}, 23 \% \mathrm{NaO}, 20 \%$ $\mathrm{CaO}$ and $4 \% \mathrm{P}_{2} \mathrm{O}_{5}$ ) was first melted and then cast into a graphite mould. After annealing, the glass was crushed, sieved into 300 to $500 \mu \mathrm{m}$ granules and sintered into cylinder shapes using a graphite mould at $720{ }^{\circ} \mathrm{C}$ for $90 \mathrm{~min}$. The final dimensions of the scaffolds were $5 \times 15 \mathrm{~mm}$. Designated BAG scaffolds were dip coated with an acid-terminated PLGA called PDLG5002A at a $50: 50$ ratio between DL-lactide and glycolide (Corbion, Gorinchem, the Netherlands). The theoretical minimum degradation time of the utilised PLGA is $14 \mathrm{~d}$ (Cyphert et al., 2020). After coating, the BAG-S53P4-PLGA scaffolds were dried in air and vacuum. All scaffolds were sterilised by gamma irradiation with a dose of $25 \mathrm{kGy}$. The average mass of the scaffolds was $351.9 \pm 13.6 \mathrm{mg}$ and the average mass of the coating for selected scaffolds was $35.0 \pm 4.7 \mathrm{mg}$. For cell stimulations, scaffolds were randomised to minimise possible effects of variability in glass scaffold and coating mass.

\section{Cell culture and stimulation with intact scaffolds Monocyte isolation and differentiation}

h-PBMCs were isolated from buffy coats of healthy volunteer blood donors who provided signed informed consent. Buffy coats were by-products of blood preparation for clinical purposes, and their use for monocyte isolation was approved by the Finnish Red Cross Blood Service. The donors were 2 men and 2 women with a mean age of 39 years; the reported data include analysis from all four specimens $(n=4)$. Mononuclear cells were isolated and differentiated into macrophages, following a previously described protocol (Nurmi et al., 2017). Briefly, blood samples were diluted in $\mathrm{Ca} / \mathrm{Mg}$-free PBS, carefully added on top of a Ficoll-Paque PLUS density gradient medium (Supplier, city, state, country), and centrifuged at $800 \times g$ for $30 \mathrm{~min}$. The mononuclear cell layer was collected and washed 4 times with PBS. Freshly isolated monocytes were then suspended in Dulbecco's modified Eagle's medium (Sigma-Aldrich, Saint Louis, MO, USA) supplemented with $1 \%$ penicillin-streptomycin antibiotic solution (Gibco, Life Technologies, Grand Island, NY, USA), counted using a TC20 automated cell counter (Bio-Rad, Hercules, CA, USA), and plated onto 24-well culture plates (well surface area $1.9 \mathrm{~cm}^{2}$ ) (Greiner Cellstar, Kremsmünster, Austria) at a concentration of $1.5 \times 10^{6}$ cells/well. Cells were allowed to adhere for $1 \mathrm{~h}$ in a humidified $37^{\circ} \mathrm{C}$ incubator at $5 \% \mathrm{CO}_{2}$ and were then rinsed twice with PBS to remove non-adherent cells. Adherent monocytes were differentiated into macrophages during a $7 \mathrm{~d}$ culture in macrophage SFM (Gibco), supplemented with $100 \mathrm{U} / \mathrm{mL}$ penicillin, $100 \mu \mathrm{g} /$ $\mathrm{mL}$ streptomycin, and $10 \mathrm{ng} / \mathrm{mL}$ GM-CSF (Miltenyi Biotec, Bergisch Gladbach, Germany).

\section{Macrophage stimulation with scaffolds}

To study the inflammatory response indirectly induced by BAG-S53P4 ( \pm PLGA), scaffolds were introduced to macrophage cultures 1 scaffold/well and incubated for 6 or $24 \mathrm{~h}$. At a given timepoint, scaffolds were removed from the wells, culture supernatants were collected, and cells disrupted by adding RLT Plus lysis buffer (Qiagen, Valencia, CA, USA). Culture media and cell lysates were stored at $-75{ }^{\circ} \mathrm{C}$ for later use. To study the indirect immunomodulatory effect of BAGs, BAG-S53P4 and BAG-S53P4-PLGA scaffolds were introduced to the wells on day 6 of macrophage culturing, thereby allowing the scaffolds to interact with cells for $24 \mathrm{~h}$. On day 7 , culture media were further supplemented with $100 \mathrm{ng} / \mathrm{mL}$ LPS (Sigma-Aldrich) for either 6 or $24 \mathrm{~h}$. At both timepoints, cell lysates and media samples were obtained as described above. LPS concentration was chosen based on a previous investigation (Day and Boccaccini, 2005). All stimulations were performed in duplicate wells, with appropriate controls included. Cell lysates from the $6 \mathrm{~h}$ timepoint were directed to qPCR analysis, whereas media samples from the $24 \mathrm{~h}$ stimulation were analysed using ELISA. Cell viability was measured from the culture media using an LDH detection kit (Roche Diagnostics, Basel, Switzerland) according to the manufacturer's instructions.

\section{ELISA}

Concentrations of the cytokines TNF $\alpha$, IL-1 $\beta$, IL-6 and IL-1Ra were analysed from $24 \mathrm{~h}$ macrophage culture media using sandwich ELISA (DuoSet kits, R\&D Systems, Minneapolis, MN), according to the manufacturer's instructions. The pro-inflammatory cytokines TNF $\alpha$, IL-1 $\beta$, and IL-6 are central for 
initiating the fracture repair (bone regeneration) cascade (Einhorn et al., 1995; Gerstenfeld et al., 2003; Lange et al., 2010). The initial inflammatory response to these factors includes recruitment of inflammatory and other cells necessary for bone regeneration and promotion of angiogenesis (Barnes et al., 1999). IL1 Ra regulates the effects of IL- $1 \beta$ and is regarded as an anti-inflammatory cytokine (Arend et al., 1998).

\section{Evaluation of LPS binding to scaffold}

Possible LPS binding to BAG-S53P4 ( \pm PLGA) scaffolds was explored by simulating the macrophagestimulation experiment on a 24-well plate (well surface area $1.9 \mathrm{~cm}^{2}$ ) (Cellstar). BAG-S53P4 and BAGS53P4-PLGA scaffolds were immersed in complete macrophage culture medium and incubated for $24 \mathrm{~h}$ in a $37{ }^{\circ} \mathrm{C}$ incubator. Thereafter, media were supplemented with $100 \mathrm{ng} / \mathrm{mL}$ of LPS and incubated for an additional 6 or $24 \mathrm{~h}$. Medium without a scaffold served as a positive control. LPS levels were determined from these media following the manufacturer's protocol using a LAL quantitation kit (Pierce LAL Chromogenic Endotoxin Quantitation Kit, Thermo Scientific, Waltham, MA, USA) and serial dilutions of endotoxin standards.

\section{$\mathrm{Rb}-\mathrm{MSC}$ stimulation}

To study the indirect osteogenic properties of BAG-S53P4 ( \pm PLGA) scaffolds, Rb-MSCs (Cat. No. RBXMX-01001, Oricell, Cyagen Biosciences Inc., CA, USA) in phase P4 were cultured on a 12-well culture plate (well surface area $3.9 \mathrm{~cm}^{2}$ ) (Cellstar) in Oricell BM (Cat. Nr. GUXMX-90011, Cyagen Biosciences
Inc.) with a cell count of $1.2 \times 10^{4}$ cells/well. RbMSC were selected because rabbit in vivo models were used in past experiments. Furthermore, these cells have been shown to closely resemble human MSCs in osteogenesis experiments (Tan et al., 2013; Zomer et al., 2018). The culture plates were coated with $0.1 \%$ porcine gelatine (Immunoassay grade gelatine, product nr. 1706537, Bio Rad, USA) prior to seeding and cells were allowed to reach $70 \%$ to $80 \%$ confluence before the start of the experiment. The scaffolds were immersed in wells with the MSCs in a total medium volume of $2 \mathrm{~mL}$. Oricell MSC OM (Cat. Nr. GUXMX-90021, Cyagen Biosciences Inc.) and Oricell MSC growth medium without scaffolds were used as positive and negative controls, respectively. Cells were refreshed every $3 \mathrm{~d}$ until the end of the experiment at $11 \mathrm{~d}$, at which point mineralisation was assessed. This early timepoint (11 d) for mineralisation assessment was chosen based on a pilot study, where mineralisation was seen in the control cells after $14 \mathrm{~d}$ of stimulation. The aim was to demonstrate that mineralisation occurs earlier in scaffold-stimulated cells than in control cells and to possibly evaluate the differences between the non-coated and coated BAG-S53P4 scaffolds. To exclude the possibility of mineralisation due to mineral precipitation from BAG on the cell culture plate surface, an identical mineralisation experiment was conducted without cells present. In addition, cell lysate samples were collected at 3 and $7 \mathrm{~d}$ timepoints. These experiments, with or without Rb-MCSs, were repeated independently 3 times $(n=3)$. Cell media samples from 1 experiment $(n=1)$ were collected at

Table 1. Primer sequences used for qPCR analysis of human macrophages.

\begin{tabular}{|c|l|l|}
\hline Gene & Primer & \multicolumn{1}{c|}{ Primer sequence $\mathbf{( 5}^{\prime} \mathbf{- 3}^{\prime}$ ) } \\
\hline \multirow{2}{*}{$T N F \alpha$} & $\begin{array}{l}\text { Forward } \\
\text { Reverse }\end{array}$ & $\begin{array}{l}\text { TGCTGCACTTTGGAGTGATCG } \\
\text { ATCTCTCAGCTCCACGCCATT }\end{array}$ \\
\hline \multirow{2}{*}{$I L-1 \beta$} & $\begin{array}{l}\text { Forward } \\
\text { Reverse }\end{array}$ & $\begin{array}{l}\text { TGGCAATGAGGATGACTTGT } \\
\text { GGAAAGAAGGTGCTCAGGTC }\end{array}$ \\
\hline \multirow{2}{*}{ RPLPO } & $\begin{array}{l}\text { Forward } \\
\text { Reverse }\end{array}$ & $\begin{array}{l}\text { GAAATCCTGAGTGATGTGCAGC } \\
\text { TCGAACACCTGCTGGATGAC }\end{array}$ \\
\hline
\end{tabular}

Table 2. Primer sequences used for qPCR analysis of Rb-MSCs.

\begin{tabular}{|c|c|c|c|c|}
\hline Gene & Primer & Primer sequence $\left(5^{\prime}-3^{\prime}\right)$ & Acc no. & Product \\
\hline RUNX2 & $\begin{array}{l}\text { Forward } \\
\text { Reverse }\end{array}$ & $\begin{array}{l}\text { TCTGGCCTTCCACTCTCAGT } \\
\text { TGCATTCGTGGGTTGGAGAA }\end{array}$ & AY598934.1 & $127 \mathrm{bp}$ \\
\hline FMOD & $\begin{array}{l}\text { Forward } \\
\text { Reverse }\end{array}$ & $\begin{array}{l}\text { ATCCTGCTGGACCTGAGCTA } \\
\text { GGGACGGTGTAGACGTTGTT }\end{array}$ & AF020291 & 104 bp \\
\hline OGN & $\begin{array}{l}\text { Forward } \\
\text { Reverse }\end{array}$ & $\begin{array}{l}\text { CTGCCAGAAAGTTTGCGTG } \\
\text { GCCСTCCAGCCGTATTTCTT }\end{array}$ & AF487889 & $129 \mathrm{bp}$ \\
\hline HPRT1 & $\begin{array}{l}\text { Forward } \\
\text { Reverse }\end{array}$ & $\begin{array}{l}\text { ACGTCGAGGACTTGGAAAGG } \\
\text { GGGCTACAATGTGATGGCCT }\end{array}$ & NM_001105671 & $111 \mathrm{bp}$ \\
\hline
\end{tabular}


$6 \mathrm{~h}, 1 \mathrm{~d}, 3 \mathrm{~d}, 7 \mathrm{~d}$ and $11 \mathrm{~d}$ timepoints for ICP-OES analysis.

\section{RT-qPCR}

Total RNA was extracted and purified from macrophage and Rb-MSC lysates using an RNeasy Mini Kit (Qiagen) according to the manufacturer's protocol. The amount of RNA was measured using a NanoDrop ${ }^{\mathrm{TM}} 1000$ spectrophotometer (Thermo Scientific) and $100 \mathrm{ng}$ of isolated RNA from each sample was reverse transcribed into cDNA using an iScript cDNA synthesis kit (Bio-Rad). Quantitative real-time PCR was performed in a LightCycler instrument (Roche) in duplicate wells. The qPCR reaction mix consisted of HOT FIREPol EvaGreen qPCR SuperMix reagent (Solis BioDyne, Tartu, Estonia), $20 \mathrm{ng}$ of sample cDNA, and primer mix (forward and reverse primers). For negative controls, the cDNA sample volume was substituted with RNase-free water.

To evaluate the inflammatory response of human macrophages to BAG-S53P4 ( \pm PLGA) scaffolds, the relative expressions of TNF $\alpha$ and $I L-1 \beta$ were analysed at the $6 \mathrm{~h}$ timepoint. NCBI/Primer-BLAST was used to design PCR primers (Table 1). The results were normalised to the housekeeping gene RPLPO.

To measure the osteogenic differentiation response of Rb-MSCs to BAG-S53P4 ( \pm PLGA) scaffolds, the relative expression of RUNX2, FMOD, and $O G N$ were analysed at the 3 and $7 \mathrm{~d}$ timepoints. Primers for these genes are listed in Table 2. Results were normalised to the housekeeping gene HPRT1.

\section{Mineralisation assay}

The mineralisation assay was conducted on $\mathrm{Rb}$ MSCs after the $11 \mathrm{~d}$ stimulation with BAG-S53P4 ( \pm PLGA) scaffolds. Quantitative measurement of mineralisation was evaluated with OsteoImage ${ }^{\mathrm{TM}}$ mineralisation assay (Lonza, Basel, Switzerland). The assay was conducted according to the manufacturer's instructions. Briefly, following removal of media, Rb-MSCs were fixed with $4 \%$ PFA for $30 \mathrm{~min}$ and incubated with staining solution for $30 \mathrm{~min}$ at room temperature. The quantitative fluorescence was measured at $480 / 520 \mathrm{~nm}$ excitation/emission wavelengths (Hidex, Turku, Finland / Spark, Tecan Trading AG, Männedorf, Switzerland). Due to critical equipment failure, 2 different fluorescence readers were used in the study and a correction factor was calculated to harmonise the results between the readers.

\section{AR stain}

Mineralisation of BAG-S53P4 ( \pm PLGA) scaffoldstimulated Rb-MSC cultures and mineralisation of control wells without cells were assessed qualitatively at the $11 \mathrm{~d}$ timepoint by staining the calcium deposits with AR (Cyagen Biosciences Inc.). Cells were fixed with $4 \%$ PFA for 30 min and stained with AR solution for $5 \mathrm{~min}$ at room temperature. Control wells without cells were also incubated in $4 \%$ PFA to produce similar conditions to the experiment performed with cells. After washing with PBS, the wells images of the cells were captured. AR staining identifies calcium deposits while OsteoImage ${ }^{\mathrm{TM}}$ binds to HA and thus these 2 methods of determining bone formation were complementary to each other.

\section{ICP-OES}

The concentrations of the elements $\mathrm{Si}, \mathrm{Ca}$ and $\mathrm{P}$ were analysed from the culture medium of Rb-MSCs incubated with BAG-S53P4 ( \pm PLGA) scaffolds using ICP-OES (Optima 5300 DV; Perkin Elmer, Waltham, MA, USA).

\section{SEM and EDX}

BAG-S53P4 ( \pm PLGA) scaffolds, used in Rb-MSCs stimulation, were collected and analysed by SEM and EDX after $11 \mathrm{~d}$ of immersion in Oricell MSC growth medium. The reaction layers that formed on the scaffold surfaces were viewed using a Leo Gemini 1530 SEM instrument equipped for electrondispersive X-ray analysis (Carl Zeiss, Oberkochen, Germany / EDX Thermo Electron Company). The scaffold cross-sections were imaged from scaffolds that had been cast to epoxy, cut to reveal the crosssections, and then polished using $\mathrm{SiC}$ papers before the analysis.

\section{pH measurements}

The $\mathrm{pH}$ measurements of cell culture media (macrophage-SFM and Oricell Rb-MSC basal growth medium) with and without the presence of BAGS53P4 ( \pm PLGA) scaffolds in a 12-well cell culture plate (Cellstar) were conducted using a Thermo Scientific ${ }^{\mathrm{TM}}$ Orion $^{\mathrm{TM}}$ PerpHecT ${ }^{\mathrm{TM}} \mathrm{ROSS}^{\mathrm{TM}}$ Combination $\mathrm{pH}$ Micro Electrode (Thermo Scientific). The experiment was performed without the presence of cells but otherwise in an identical setting compared with the above-mentioned experiments with macrophages and $\mathrm{Rb}-\mathrm{MSC}$. The $\mathrm{pH}$ was measured at baseline (i.e. before scaffold introduction) and at $15 \mathrm{~min}, 30 \mathrm{~min}$, $1 \mathrm{~h}, 6 \mathrm{~h}$ and $1 \mathrm{~d}$ in both media and additionally at $3 \mathrm{~d}$, $7 \mathrm{~d}$ and $11 \mathrm{~d}$ timepoints for the Oricell Rb-MSC basal growth medium. The measurements were taken from triplicate wells $(n=3)$.

\section{Statistical analyses}

Statistical analyses were performed using GraphPad Prism version 8 (GraphPad Software, La Jolla, CA, USA). The experiments with human primary macrophages $(n=4)$ were analysed using Friedman's test and Dunn's multiple comparison tests. For other experiments, consisting of three parallel samples $(n=3)$, statistical comparison between groups was conducted by one-way ANOVA followed by Holm-Sidak's post-hoc tests. $p<0.05$ was chosen as the threshold for statistical significance. Results are presented as mean \pm standard error of mean. 
a
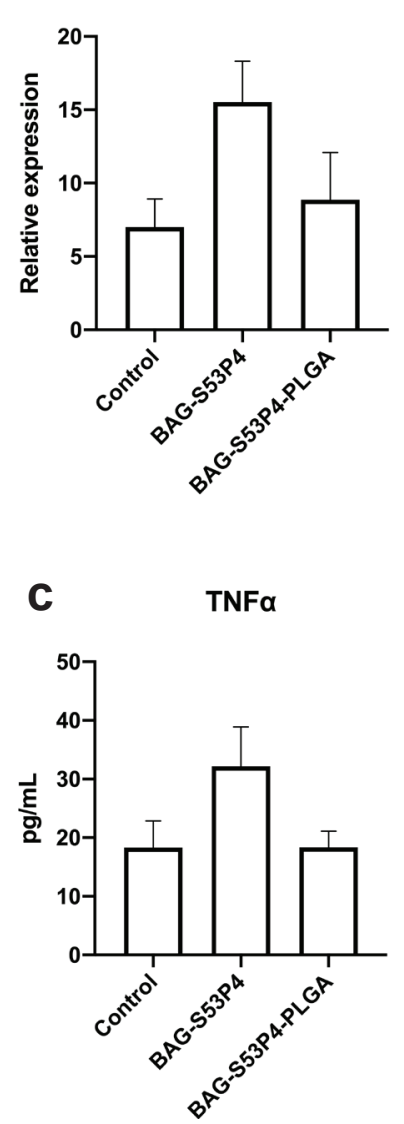

a
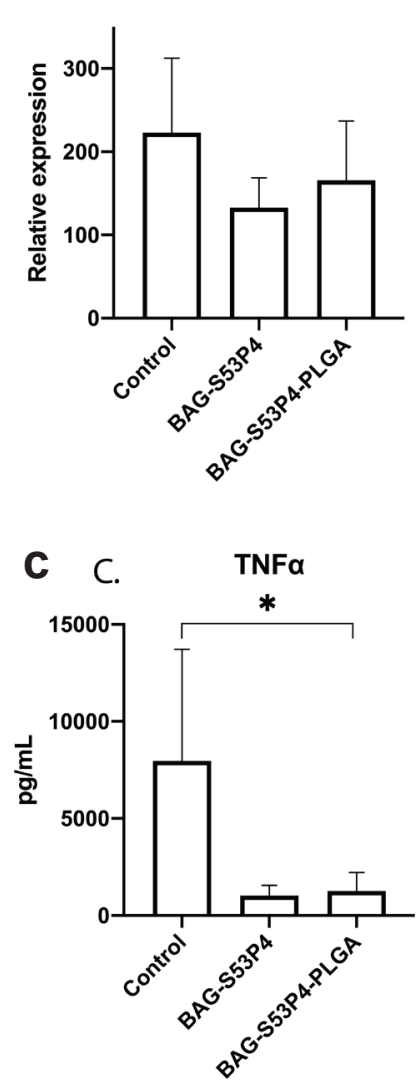

b

IL-1 $\beta$

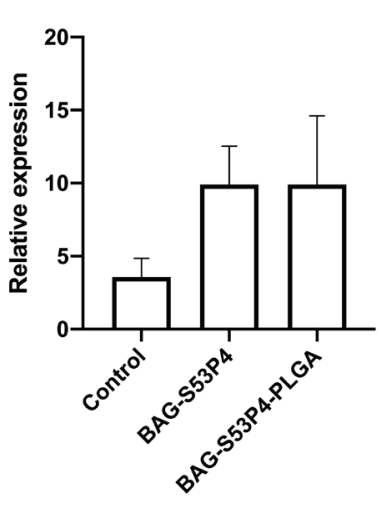

d

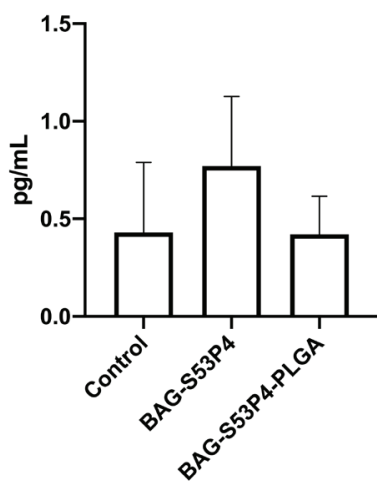

b

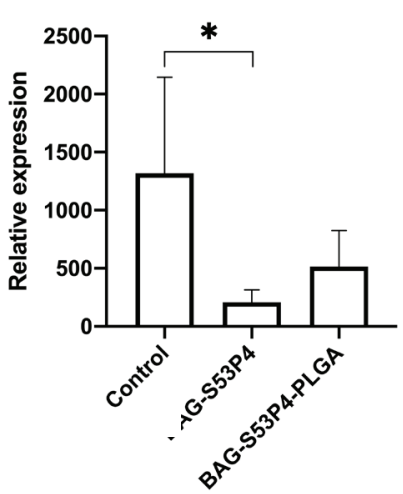

e

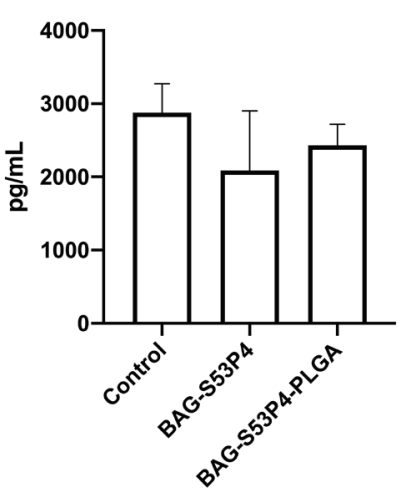

Fig. 1. Scaffold stimulation of macrophages without LPS treatment. Human primary macrophages were stimulated with BAG-S53P4 ( \pm PLGA) scaffolds for 6 and $24 \mathrm{~h}$ and the inflammatory response was assessed by qPCR and ELISA. Relative mRNA expression of (a) TNF $\alpha$ and (b) IL-1 $\beta$ were determined after $6 \mathrm{~h}$ of scaffold stimulation, whereas cytokine secretion for (c) TNF $\alpha$, (d) IL-1 $\beta$, (e) IL-6, and (f) IL-1Ra were measured at the $24 \mathrm{~h}$ timepoint $\left({ }^{*}=p<0.05\right)$.
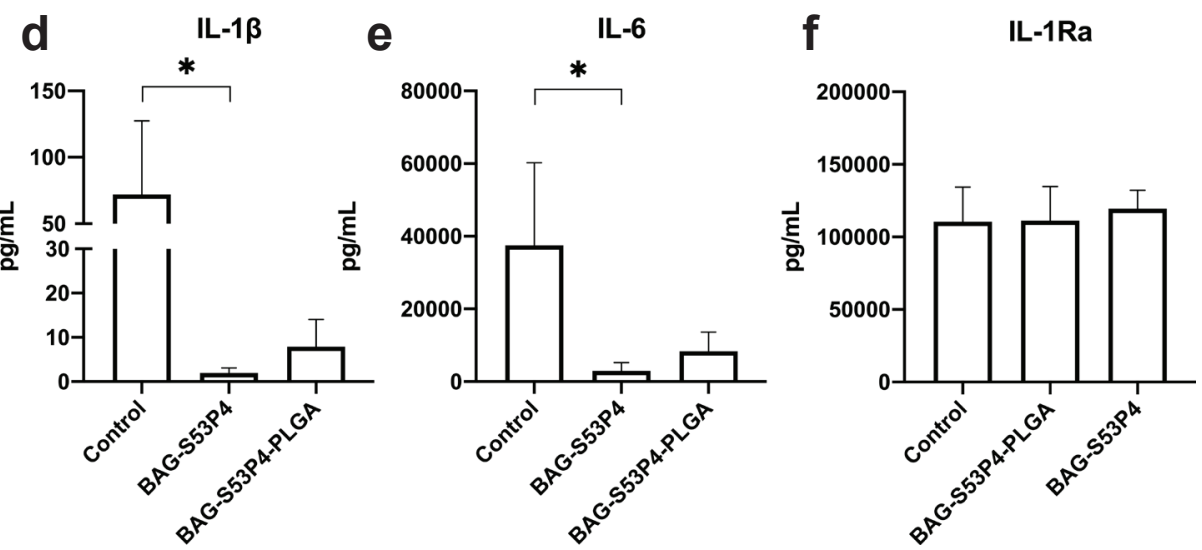

Fig. 2. Immunomodulatory effect of scaffolds on
LPS-challenged macrophages. Human primary macrophages were preincubated with BAG-S53P4 ( \pm PLGA) scaffolds for $24 \mathrm{~h}$, after which the culture media were further supplemented with LPS for 6 or $24 \mathrm{~h}$. The relative mRNA expression of (a) TNF $\alpha$ and (b) IL-1 $\beta$ were determined by qPCR after $6 \mathrm{~h}$ of LPS stimulation. Secretion of pro-inflammatory cytokines (c) TNF $\alpha$, (d) IL-1 $\beta$, and (e) IL-6 and antiinflammatory cytokine (f) IL-1Ra were assessed, following a $24 \mathrm{~h}$ LPS challenge, using ELISA $\left({ }^{*}=p<0.05\right)$.

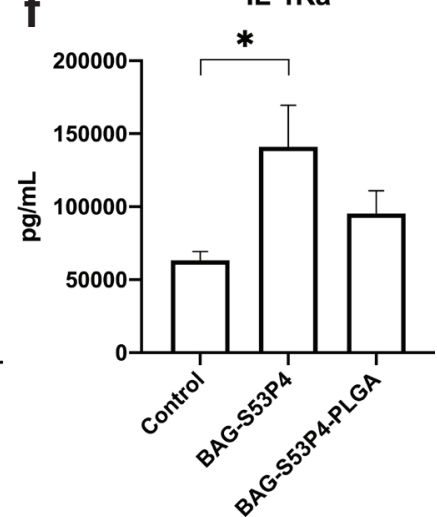




\section{Results}

\section{Inflammatory reaction to scaffolds in vitro}

The potential inflammatory reaction, elicited by BAG-S53P4 ( \pm PLGA) scaffolds, was evaluated in a human macrophage culture model. Introduction of BAG-S53P4 ( \pm PLGA) scaffolds to macrophages did not induce the expression of TNF $\alpha$ or IL-1 $\beta$ mRNA at the $6 \mathrm{~h}$ timepoint, as analysed by qPCR (Fig. 1a,b). Similarly, macrophages challenged with BAG-S53P4 ( \pm PLGA) scaffolds for $24 \mathrm{~h}$ did not elicit significant production of the pro-inflammatory cytokines TNF $\alpha$, IL-1 $\beta$ and IL-6, as assessed by ELISA (Fig. 1c-e). In contrast, secretion of the anti-inflammatory cytokine IL-1Ra was elevated at $24 \mathrm{~h}$ by BAG-S53P4 ( \pm PLGA) scaffolds; the non-coated BAG-S53P4 exhibited significantly higher IL-1Ra production compared with control samples (Fig. 1f). However, the difference in IL-1Ra concentrations between BAGS53P4 and BAG-S53P4-PLGA was not significant.

\section{Anti-inflammatory effects of scaffolds in vitro}

The immunomodulatory properties of the BAGS53P4 ( \pm PLGA) scaffolds were assessed using cultured human macrophages challenged with LPS. As expected, LPS stimulation markedly upregulated the mRNA expression of TNF $\alpha$ and $I L-1 \beta$ after $6 \mathrm{~h}$, as assessed by qPCR (Fig. 2a,b). Similarly, LPS-challenged macrophages exhibited markedly elevated secretion of the pro-inflammatory cytokines TNF $\alpha$, IL- $1 \beta$ and IL- 6 at 24 h, as assessed by ELISA.

Interestingly, preincubation of macrophages with BAG-S53P4 ( \pm PLGA) scaffolds, prior to and during the LPS challenge, seemed to lower the relative mRNA expressions of TNF $\alpha$ and IL-1 $\beta$ when compared with cells stimulated with LPS alone (Fig. 2a,b). This reduction in IL-1 $\beta$ expression was statistically significant for BAG-S53P4-treated macrophages (Fig. 2b). A similar trend was observed when analysing the secretion of TNF $\alpha$, IL- $1 \beta$ and IL6; macrophages stimulated with LPS in combination with the BAG-S53P4 ( \pm PLGA) scaffolds exhibited decreased secretion of these pro-inflammatory cytokines (Fig. 2c-e). LPS-challenged macrophages incubated with BAG-S53P4 ( \pm PLGA) scaffolds showed no difference in TNF $\alpha$ secretion. However, a statistically significant difference was noted for BAGS53P4-PLGA when compared with control cells (Fig. 2c). PLGA coating, however, marginally elevated IL$1 \beta$ and IL- 6 concentrations when compared with the non-coated BAG-S53P4 scaffold (Fig. 2d-e). Although clear trends were seen in the pro-inflammatory immunomodulation of BAG-S53P4 ( \pm PLGA) scaffolds on LPS-challenged human macrophages, only a few statistically significant differences were observed, due to high donor variability between the 4 donors. The concentration of the anti-inflammatory cytokine IL-1Ra remained unaffected by BAG-S53P4 ( \pm PLGA) scaffold stimulation as compared with control cells (Fig. 2f).
To determine if the observed immunomodulatory effects could be artefacts due to cytotoxicity or nonspecific binding of LPS on the porous scaffold, cell viability and the LPS recovery rates after scaffold incubations were assessed. The scaffold-induced
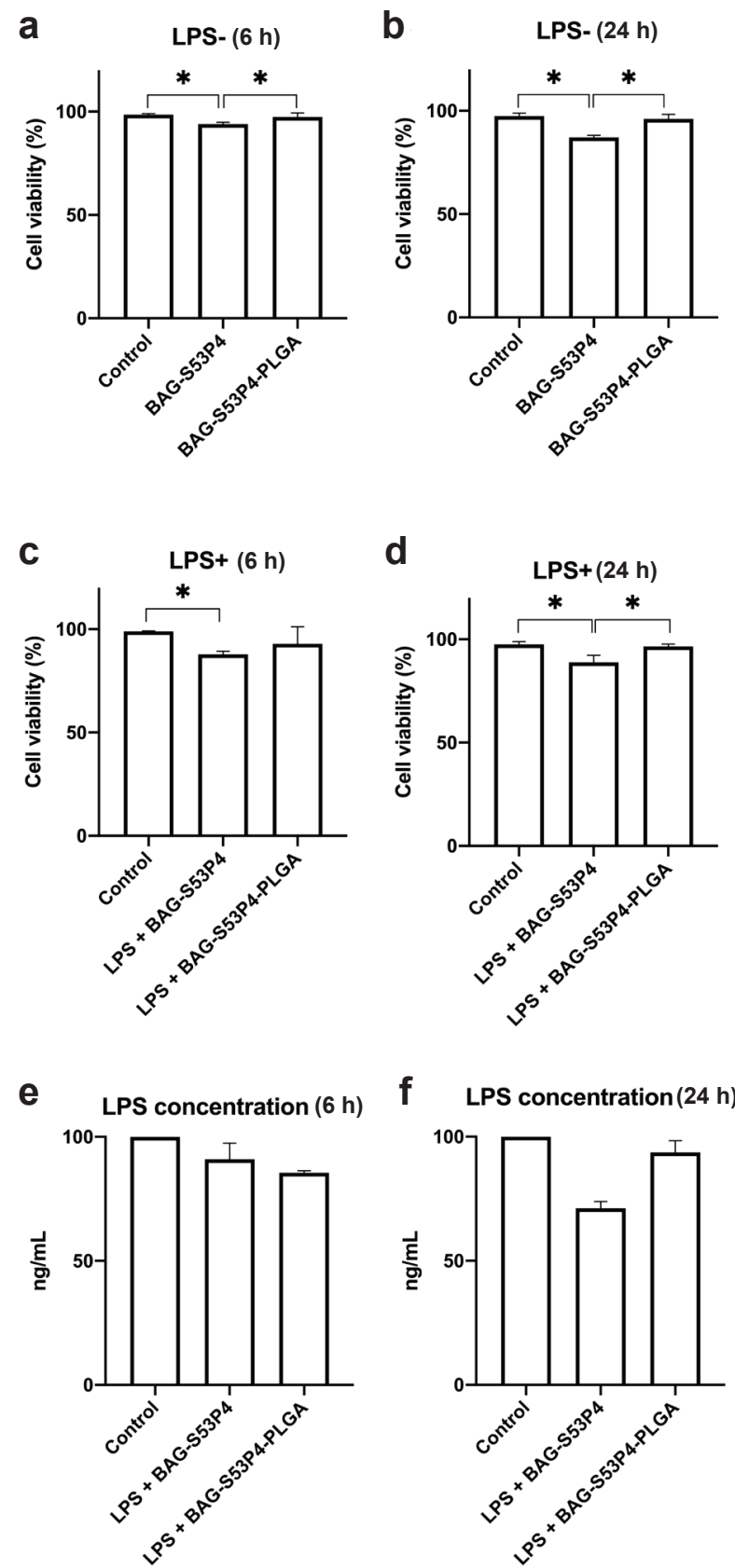

Fig. 3. Cell viability of macrophages and LPS binding to the scaffold. Human primary macrophages were incubated in the presence of BAG-S53P4 $( \pm$ PLGA) scaffolds and scaffold-induced cytotoxicity was determined at (a) $6 \mathrm{~h}$ and (b) $24 \mathrm{~h}$ timepoints using an LDH assay. The combined effects of scaffold preincubation and subsequent LPS challenge on cell viability were analysed after (c) 6 and (d) $24 \mathrm{~h}$ of LPS treatment. Binding of LPS to the surface of preincubated scaffolds was assessed using a LAL assay after (e) $6 \mathrm{~h}$ and (f) $24 \mathrm{~h}$ of LPS stimulation. * indicates statistically significant difference between conditions $\left({ }^{*}=p<0.05\right)$. 
a

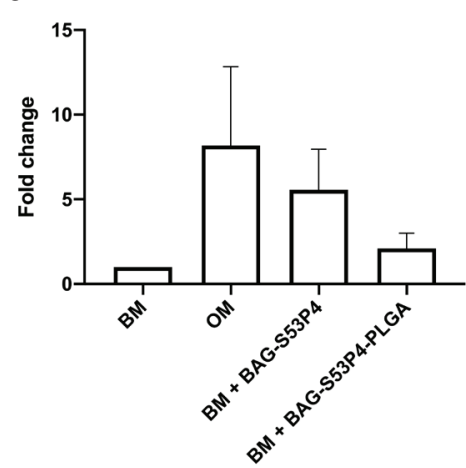

d

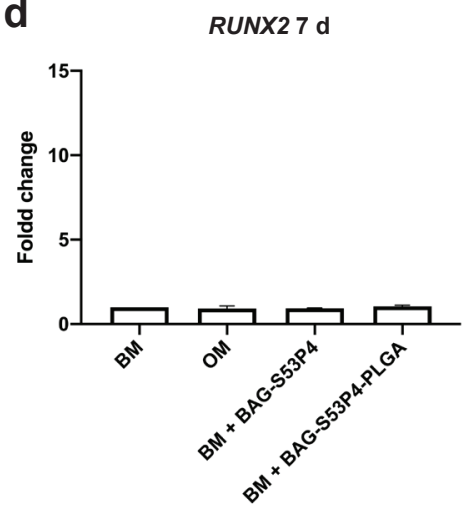

b

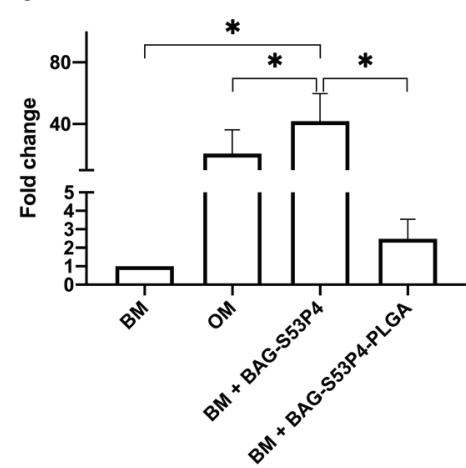

e

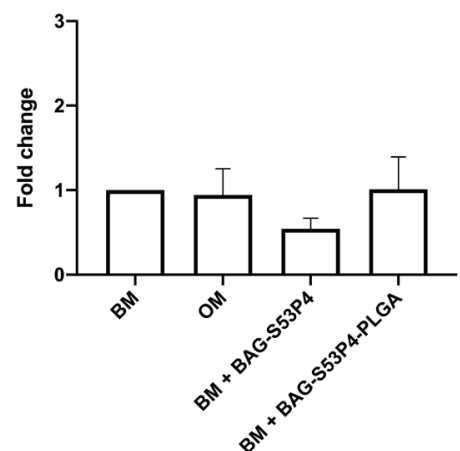

C

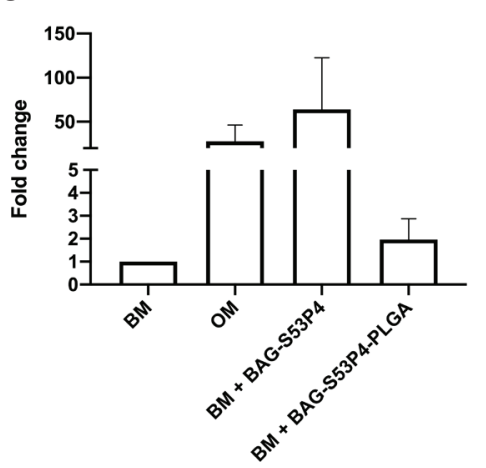

f

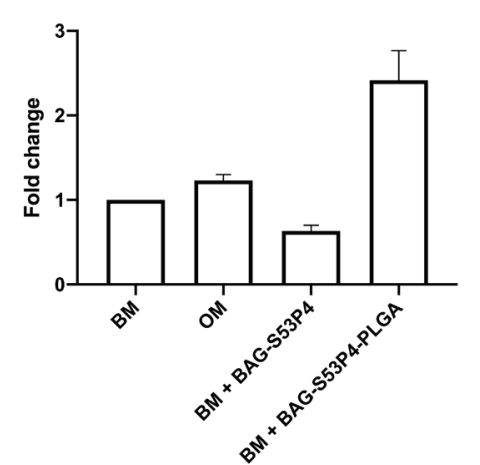

Fig. 4. Relative mRNA expression of osteogenic markers. Rb-MSCs were cultured in the presence of BAGS53P4 ( \pm PLGA) scaffolds and their relative mRNA expression of RUNX2, FMOD and OGN was analysed after (a-c) 3 and (d-f) 7 d. Cells cultured in osteogenic differentiation medium (OM) served as a positive control. Results are presented as fold change compared with unstimulated control cells cultured in basal MSC growth medium (BM) $\left(^{*}=p<0.05\right)$.

cytotoxicity in human macrophage cultures was evaluated by measuring LDH release. Compared with controls, a modest decrease in cell viability was observed in the scaffold groups (Fig. 3a,b). This effect was slightly enhanced by the addition of LPS (Fig. 3c,d). BAG-S53P4 scaffolds induced higher cytotoxicity when compared with control and BAGS53P4-PLGA groups.

Some LPS binding occurred on the scaffold surfaces, as slightly reduced LPS amounts were recovered from the media of the scaffold groups after 6 and $24 \mathrm{~h}$ culture (Fig. 3e,f). These differences, however, were not statistically significant.

\section{Induction of osteogenesis in rabbit MSC cultures} As analysed by qPCR, Rb-MSCs stimulated with BAG-S53P4 scaffolds showed elevated mRNA expression of osteogenic markers RUNX2, FMOD, and OGN after $3 \mathrm{~d}$ of culturing (Fig. $4 \mathbf{a}-\mathbf{c}$ ). Of these changes, the increase in $F M O D$ expression reached statistical significance (Fig. 4b). A similar response profile was observed for cells cultured in OM. In contrast, PLGA-coated scaffolds induced low mRNA levels of these markers at the $3 \mathrm{~d}$ timepoint. After $7 \mathrm{~d}$, the mRNA expression of RUNX2, FMOD, and OGN in OM cells and BAG-S53P4 ( \pm PLGA) cells had returned to the level of unstimulated control cells cultured in basal MSC growth medium (BM)

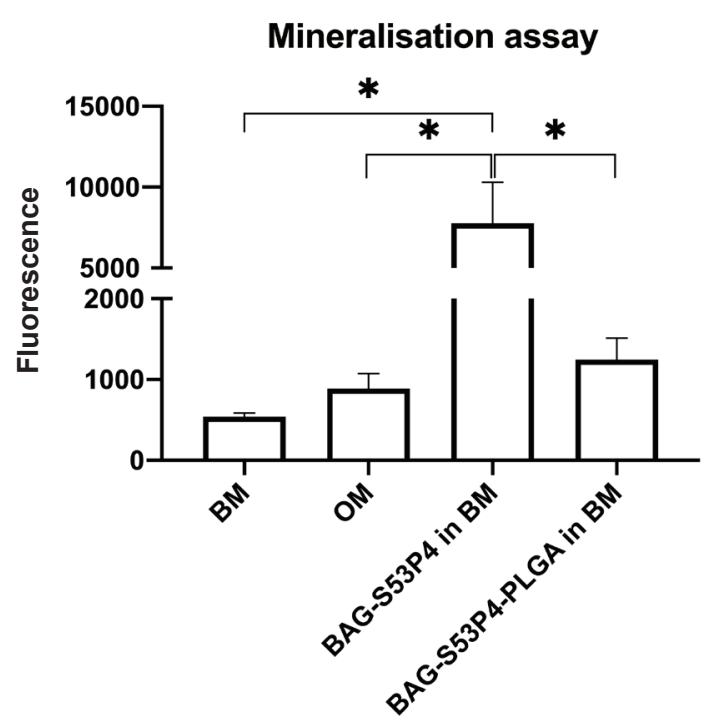

Fig. 5. Scaffold-induced mineralisation measured using OsteoImage ${ }^{\mathrm{TM}}$ assay. $\mathrm{Rb}-\mathrm{MSC}$ s were cultured in the presence of BAG-S53P4 ( \pm PLGA) scaffolds for $11 \mathrm{~d}$ and culture mineralisation was assessed using an OsteoImage ${ }^{\mathrm{TM}}$ assay. Cells in osteogenic differentiation medium (OM) and basal MSC growth medium (BM) served as controls. ${ }^{*}$ indicates statistically significant difference between conditions $\left(^{*}=p<0.05\right)$. 
(Fig. 4d-f). Interestingly, Rb-MSCs stimulated with BAG-S53P4-PLGA scaffolds still maintained slightly increased, but not statistically significant, OGN expression after $7 \mathrm{~d}$ (Fig. 4f). This might be due to the PLGA coating, which delays and subdues the effects of the underlying BAG.

Mineralisation of the $\mathrm{Rb}$-MSC cultures was assessed at the $11 \mathrm{~d}$ timepoint. Quantitative measurements showed that cells stimulated with BAG-S53P4 scaffolds had significantly increased mineralisation compared with all other groups (Fig. 5). Rb-MSCs stimulated with BAG-S53P4-PLGA scaffolds and cells cultured in OM induced similar levels of mineralisation; both were marginally higher than unstimulated control cells. The minimal mineralisation of OM-cultured Rb-MSCs was probably due to the shortened $11 \mathrm{~d}$ stimulation time. Corresponding mineralisation patterns were evident in qualitative AR staining (Fig. 6a-d). Of note, some calcium deposition also occurred on the bottom of the well in BM without cells, incubated with BAGS53P4 scaffolds. This mineralisation, probably due to surface precipitation of $\mathrm{Ca}$ and $\mathrm{P}$ ions dissolved from scaffold, was only seen at the site of direct scaffold contact with the cell culture well (Fig. 6eh). In contrast, in the experiments containing $\mathrm{Rb}$ MSCs, the mineralisation was evident over a wider surface area, also at sites where scaffolds were not in direct contact with the well surface. Thus, although it can be concluded that the BAG-S53P4 scaffolds stimulate mineralisation in Rb-MSC, the quantitative measurements must be interpreted with caution due to evident mineralisation of the scaffold itself.

\section{Ion release into the cell culture media}

Ion release from the BAG-S53P4 ( \pm PLGA) scaffolds in cell culture conditions was assessed using ICP-OES, in a time-course study. The Si species concentration

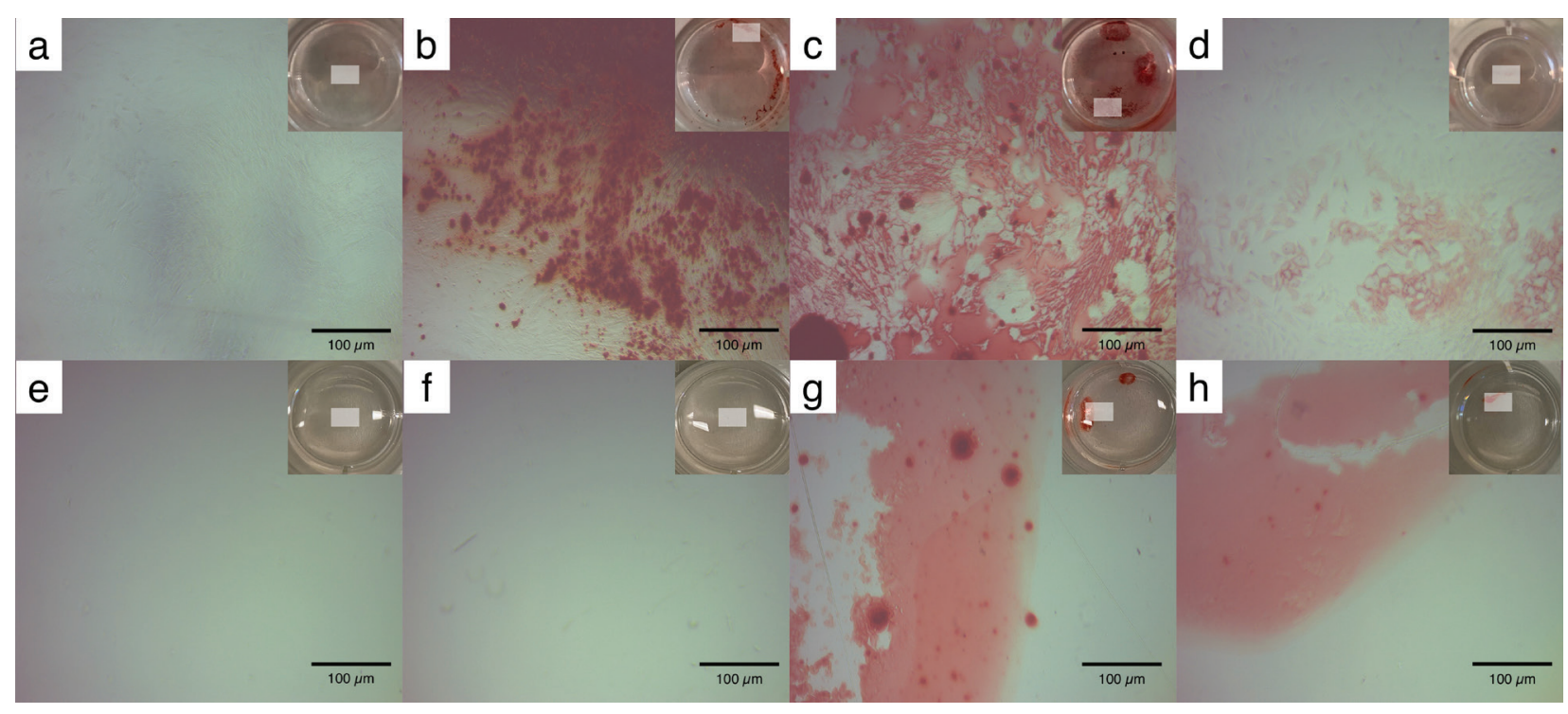

Fig. 6. Alizarin red staining. Rb-MSCs were cultured with BAG-S53P4 ( \pm PLGA) scaffolds for $11 \mathrm{~d}$ and mineralisation was assessed by AR staining. Microscopy images of representative samples are shown for (a) unstimulated control cells in basal growth media (BM), (b) cells in osteogenic differentiation medium (OM), (c) BAG-S53P4-stimulated cells, (d) BAG-S53P4-PLGA-stimulated cells, (e) BM without cells, (f) OM without cells, (g) BM stimulated with BAG-S53P4 without cells and (h) BM stimulated with BAG-S53P4PLGA without cells. Images of respective wells are embedded in the upper right corner of each micrograph and a rectangle marks the area of the microscopy image.

a

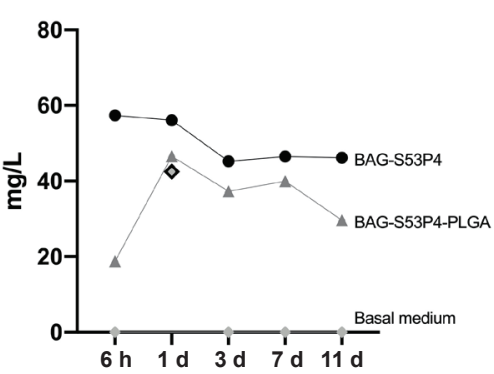

b

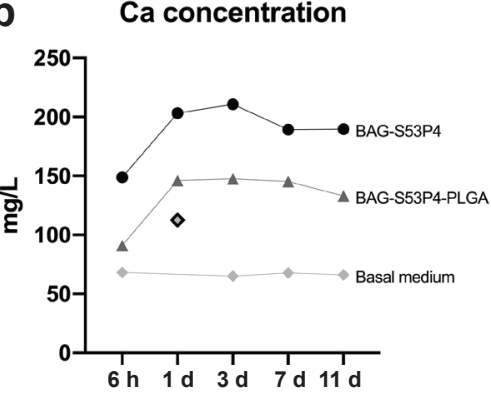

C P concentration

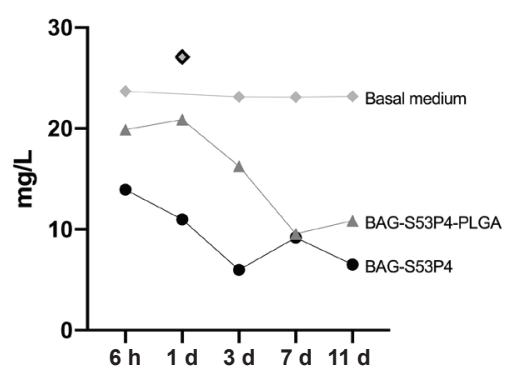

Fig. 7. Ion release from scaffolds $(n=1)$. BAG-S53P4 $( \pm$ PLGA) scaffolds were immersed in Rb-MSC cultures and the media concentration for (a) Si, (b) Ca, and (c) P was measured after a $6 \mathrm{~h}, 1 \mathrm{~d}, 3 \mathrm{~d}, 7 \mathrm{~d}$ and $11 \mathrm{~d}$ incubation time by ICP-OES. Ions in basal MSC growth medium without a scaffold were included as reference values. The $1 \mathrm{~d}$ timepoint for basal medium control was rejected because of technical error in measurement. 

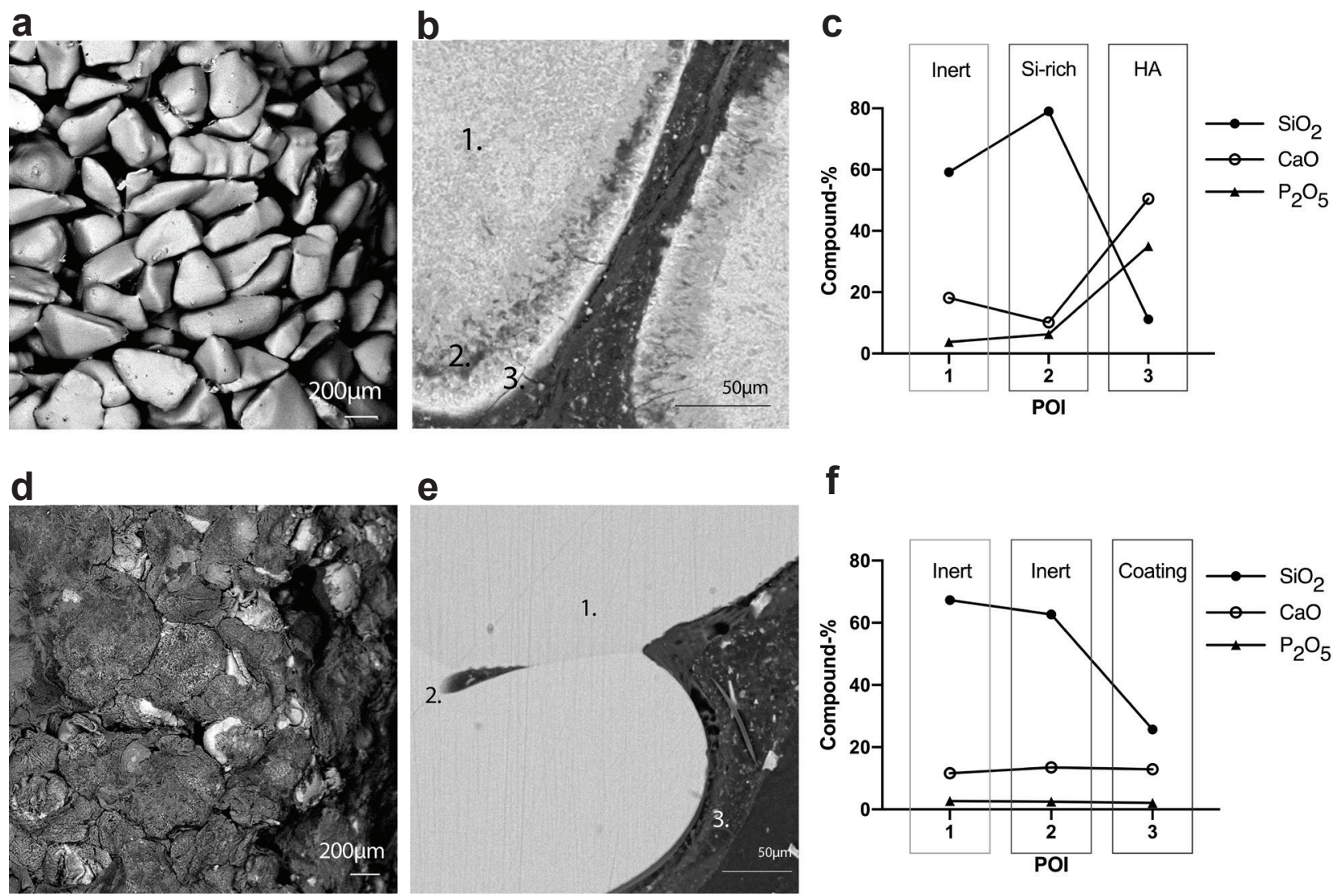

Fig. 8. SEM and EDX. SEM and EDX results of BAG-S53P4 (a-c) and BAG-S53P4-PLGA (d-f) scaffolds incubated in Rb-MSC cultures for $11 \mathrm{~d}$. Representative images are presented for non-coated scaffolds (a), their cross-sectional surface where the reaction layer is visualised (b) and the EDX results from 3 different points of interest (POI) (c). EDX measurements reveal inert BAG in the middle, a silica-rich layer and an outer layer of $\mathrm{CaP}(\mathbf{c})$. Representative images are presented for coated scaffolds (d), their cross-sectional surface with no clear formations of reaction layers (e) confirmed by EDX analysis (f). Inert BAG is seen at 2 different POI and the outermost layer represents the coating material (f). Scalebars are located in the bottom right corners of respective images.

was the highest at the $6 \mathrm{~h}$ timepoint for BAG-S53P4 and showed a decrease at the $3 \mathrm{~d}$ timepoint, after which stable concentrations were measured (range 57 to $45 \mathrm{mg} / \mathrm{L}$ ). BAG-S53P4-PLGA showed a Si peak at the $1 \mathrm{~d}$ timepoint, after which stabilisation occurred (range 19 to $47 \mathrm{mg} / \mathrm{L}$ ). As expected, Si concentrations were not detectable in the control basal media sample because the basal cell media does not contain any Si species. Due to a technical error, the $1 \mathrm{~d} \mathrm{Si}$ measurement timepoint for basal medium without scaffold was discarded (Fig. 7a).

For both coated and non-coated BAG-S53P4 scaffolds, the concentration of $\mathrm{Ca}$ ions increased until the $1 \mathrm{~d}$ timepoint, after which the concentration stabilised. At the $1 \mathrm{~d}$ timepoint, the Ca concentration was higher for BAG-S53P4 compared with BAGS53P4-PLGA (203 vs. $146 \mathrm{mg} / \mathrm{L}$ ). The Ca concentration in the basal medium alone was steady throughout the measurement period and varied from 65 to $68 \mathrm{mg} / \mathrm{L}$ (Fig. 7b).

The concentration of $\mathrm{P}$ species was highest at the $6 \mathrm{~h}$ timepoint and then declined until stabilisation after the $3 \mathrm{~d}$ timepoint. The decline was more rapid for the BAG-S53P4 scaffold, which reached a steady state at the $3 \mathrm{~d}$ timepoint, compared with the $7 \mathrm{~d}$ timepoint for the BAG-S53P4-PLGA scaffold. Overall, the concentration of $\mathrm{P}$ species was lower for the noncoated BAG-S53P4 (range 14 to $6 \mathrm{mg} / \mathrm{L}$ ) compared with coated BAG-S53P4-PLGA (range 21 to $9 \mathrm{mg} / \mathrm{L}$ ). In control basal media, the P concentration was stable during the entire measurement period (range 24 to $23 \mathrm{mg} / \mathrm{L})$ (Fig. 7c).

\section{Deposition of calcium phosphate on scaffold surfaces}

SEM images were taken from the surface of intact BAG-S53P4 ( \pm PLGA) scaffolds incubated in RbMSC cultures for $11 \mathrm{~d}$ and reaction layers were identified by EDX analysis. Formation of a calcium and phosphate-rich (CaP) layer was observed on the surface of uncoated scaffolds by cross-sectional analysis, which confirmed the EDX analysis, revealing the reaction layer on the outermost BAG particles (Fig. 8a-c). EDX analysis from three different points of interest (POI) show inert BAG in the inner part of a granule, a silica-rich layer and a outermost CaP layer (Fig. 8c). Imaging of the coated scaffolds revealed that the PLGA coating was not entirely uniform and areas of uncoated particles were present (Fig. 8e). There was markedly less layer formation on 
the surface of the PLGA-coated scaffolds and upon EDX analysis no clear layers could be identified (Fig. $8 \mathbf{e}, \mathbf{f})$. The formation of the reaction layer containing $\mathrm{CaP}$ is consistent with previous reports characterising the surface reactions of BAG-S53P4 (Fagerlund et al., 2012).

\section{$\mathrm{pH}$ of culture media}

The baseline $\mathrm{pH}$ average from triplicate wells was $7.50 \pm 0.01$ in the macrophage-SFM and $7.34 \pm 0.02$ in the BM. A peak in $\mathrm{pH}$ was noted at the $30 \mathrm{~min}$ timepoint for all samples, after which the $\mathrm{pH}$ stabilised (Fig. 9a,b). Of note, the $\mathrm{pH}$ value of BAGS53P4-PLGA in BM decreased at the $11 \mathrm{~d}$ timepoint. This might be due to continued PLGA degradation (Fig. 9b).

BAG-S53P4 significantly increased the $\mathrm{pH}$ at all timepoints compared with BAG-S53P4-PLGA and all control samples (Fig. 9a,b). BAG-S53P4-PLGA showed significant increases in $\mathrm{pH}$ values compared with macrophage-SFM and BM media control samples at the $15 \mathrm{~min}$ to $7 \mathrm{~d}$ timepoints. However, at the $11 \mathrm{~d}$ timepoint, the $\mathrm{pH}$ value of BAG-S53P4-PLGA in BM was significantly lower than control BM (Fig. $9 \mathbf{a}, \mathbf{b})$.

\section{Discussion}

In this study, the immunomodulatory and osteogenic properties of sintered BAG-S53P4 ( \pm PLGA) scaffolds were assessed in human macrophage and rabbit MSC culture models, respectively. When placed in human macrophage cultures, the BAG-S53P4 scaffolds alone did not induce a significant inflammatory reaction, as assessed by production of the pro-inflammatory cytokines TNF $\alpha$, IL- $1 \beta$ and IL- 6 . Instead, the production of the anti-inflammatory cytokine IL-1Ra was upregulated in scaffold-challenged macrophage cultures, possibly suggesting that the non-coated BAG scaffolds have anti-inflammatory properties. The PLGA coating was also found not to induce an inflammatory response, as the production of TNF $\alpha$, IL-1 $\beta$ and IL- 6 remained low in the BAGS53P4-PLGA-challenged macrophage cultures. The production of IL-1Ra, however, was attenuated by PLGA coating. In LPS-stimulated macrophages, both $\mathrm{TNF} \alpha$ and IL-1 $\beta$ gene expression levels decreased when cells were first introduced to BAG-S53P4 ( \pm PLGA) scaffolds. This anti-inflammatory effect was noted for pro-inflammatory cytokine (TNF $\alpha$, IL-1 $\beta$ and IL-6) secretion as well. Within this timeframe of $24 \mathrm{~h}$, PLGA-coated BAG-S53P4 scaffolds showed a decreased anti-inflammatory effect compared with non-coated BAG-S53P4 scaffolds rather than producing a pro-inflammatory reaction. This is in contrast to a previous study, where, in a short-term $(4 \mathrm{~h})$ experiment, PLGA microparticles produce an pro-inflammatory reaction in vitro on murine macrophages (Nicolete et al., 2011). However, the immunomodulatory effects of PLGA have also been

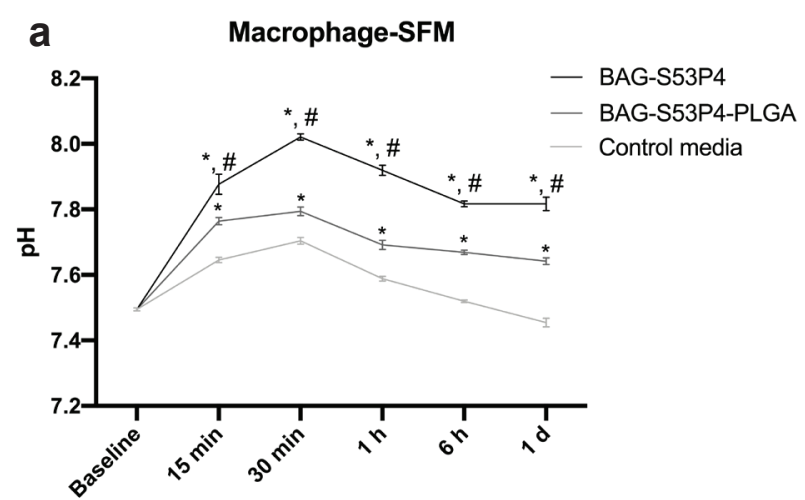

b

Rb-MSC medium

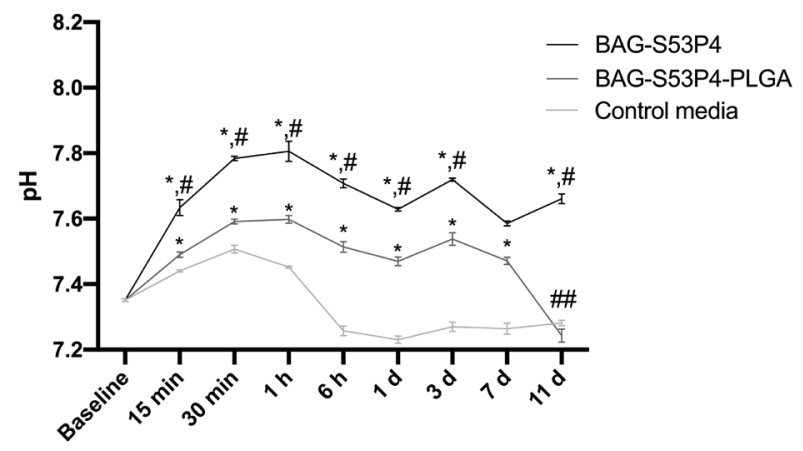

Fig. 9. Time-course pH measurements of macrophage-SFM and Oricell basal MSC growth media (BM) incubated with BAG-S53P4 ( \pm PLGA) scaffolds. The experiment was conducted in the absence of cells. (a) pH measurements in macrophageSFM and (b) $\mathrm{pH}$ measurements in BM. ${ }^{*}=$ statistical significance $(p<0.05)$ compared with control, \# = statistical significance $(p<0.05)$ of BAG-S53P4 vs. BAG-S53P4-PLGA, and \#\# = statistical significance $(p<0.05)$ of BM vs. BAG-S53P4-PLGA.

shown to be immunosuppressive in dendritic cells exposed to PLGA microparticles for longer periods (up to $120 \mathrm{~h}$ ) (Allen et al., 2018). Considering these contrasting reports, the overall immunomodulatory effect of PLGA warrants further research.

In previous in vivo experiments, differences were demonstrated in the IM characteristics with regards to TNF $\alpha$, VEGF and BMP expression between coated and non-coated BAG-S53P4 scaffolds without any obvious deleterious effects (Björkenheim et al., 2017; Björkenheim et al., 2019). The rationale behind the rapid degradation profile of the utilised PLGA minimum of $14 \mathrm{~d}$ (Cyphert et al., 2020) - was to allow the BAG-S53P4 to interact with the surroundings as early as possible to hinder the formation of a fibrotic capsule. These findings were hypothesised to be due to a stronger initial inflammatory reaction of PLGAcoated scaffolds compared to uncoated BAG-S53P4 scaffolds alone, leading to a formation of a biologically more active IM. The current results suggested that the PLGA coating functioned mainly by inhibiting and slowing down the native BAG surface reactions, which thus attenuated the innate anti-inflammatory 
properties of BAGs rather than directly inducing an inflammatory reaction. These apparently conflicting results might partially be explained by PLGAdegradation dynamics. In the relatively short time frame of the current study, only small amounts of the PLGA degradation products were likely released into the cell culture media, while in the in vivo experiments the whole coating was eventually degraded. The potential immunomodulatory properties of higher concentrations of PLGA degradation products, as well as the consequences of extended exposure to them, remain a topic for further research. Although further studies are warranted, it can be proposed that the net in vivo effect of the PLGA coating is initially pro-inflammatory, possibly due to both inhibition of BAG anti-inflammatory properties and the short-term pro-inflammatory action; at later stages, the effect is anti-inflammatory. Taken together, the sintered BAG scaffolds seem to have anti-inflammatory properties that are partially inhibited or at least slowed down by the PLGA coating. However, as previously demonstrated (Björkenheim et al., 2017; Björkenheim et al., 2019), sintered BAG-S53P4 scaffolds can induce a biologically active membrane in rabbits by having a limited inflammatory effect in vivo. Thus, the actions of BAG-S53P4 are deemed as immunomodulatory rather than purely antiinflammatory. The immunomodulatory results are consistent with previous BAG studies, although these reports have been conducted using different types of BAGs and cells (Kim et al., 2019; Varmette et al., 2009).

Although granules of BAG-S53P4 are known to have good biocompatibility and are currently used in clinical practice (Lindfors et al., 2010b), some cytotoxicity was still observed in the scaffoldcontaining macrophage cultures. This slightly increased cell death rate (non-significant) of scaffoldstimulated macrophages likely occurred due to unavoidable mechanical friction caused by the scaffold, as the scaffolds were placed directly on top of the cells partially covering the well surface. In fact, some areas of detached cells were observed underneath the scaffolds when the scaffold was removed from the wells. This probably could have been avoided by using a trans-well culture system. However, the apical pressure effect of the scaffolds on the cells would also seem to be minimal in the experimental setting, and the utilisation of a transwell setting would probably have yielded a similar result. It has been proposed that cell stimulation with BAGs leads to cellular death, due to alkalinisation of the surrounding environment. Pre-conditioning of BAG by incubation in the cell culture media prior to in vitro experiments has also been suggested (Ciraldo et al., 2018). However, no differences were found in cytotoxicity induced by pre-conditioned and nonpreconditioned BAG-S53P4 ( \pm PLGA) scaffolds in preliminary experiments (data not shown). Scaffold pre-conditioning was further confirmed to be nonsignificant in terms of its immunomodulatory effect (data not shown). Therefore, non-preconditioned
BAG scaffolds were selected for the cell culture models. Of note, this approach has also been used in previous in vivo studies (Björkenheim et al., 2017; Björkenheim et al., 2019). Moreover, the results obtained might have been affected by the tendency of LPS to bind to the scaffold surfaces. Regardless, it is believed that the effect of these factors remained relatively modest and could not alone account for the striking immunomodulatory effects detected for BAG scaffolds.

It has previously been reported that BAG-S53P4 can induce an active membrane with osteogenic potential (Björkenheim et al., 2019). Furthermore, BAG-S53P4 in granular form is associated with direct osteostimulative properties (Waselau et al., 2012). In the present study, sintered BAG-S53P4 scaffolds induced osteogenic differentiation of $\mathrm{Rb}$ MSCs; at an early $3 \mathrm{~d}$ timepoint elevated mRNA expression levels of RUNX2, FMOD, and OGN were already observed. Of these markers, transcription factor RUNX2 promotes differentiation of MSCs into osteoblasts, whereas FMOD represents a biomarker associated with the maturation process of osteoprogenitor cells (Banerjee et al., 1997; Waddington et al., 2003). OGN reportedly plays a role in later stages of the osteoblast maturation process (Tanaka et al., 2012). Strikingly, the expression levels of BAG-S53P4-induced osteogenic markers were comparable to those induced by osteogenic media. In the mineralisation assay, an attempt was made to identify if the mineralisation manifested earlier in Rb-MSCs stimulated with BAG-S53P4 ( \pm PLGA) scaffolds, when compared with cells cultured in OM alone. According to the pilot study and supplier's recommendation, a $14 \mathrm{~d}$ period is sufficient for $\mathrm{Rb}-\mathrm{MSC}$ mineralisation. Ojansivu et al. also used a $11 \mathrm{~d}$ to $14 \mathrm{~d}$ stimulation time when evaluating mineralisation from BAG extracts (Ojansivu et al., 2015). Furthermore, Rb-MSC have been shown to have a higher osteogenic potential than hMSCs (Tan et al., 2013). Thus, this $11 \mathrm{~d}$ time point was selected to evaluate if BAG-S53P4 ( \pm PLGA) scaffolds produced mineralisation even earlier than control samples and to evaluate the possible difference between the non-coated and PLGA coated BAG-S53P4 scaffolds in Rb-MSCs. At the $11 \mathrm{~d}$ timepoint, mineralisation was clearly present for BAG-S53P4-stimulated RbMSCs, whereas mineralisation of Rb-MSCs treated with OM or BAG-S53P4-PLGA scaffolds remained low. Of note, this mineralisation was observed at the site of scaffold and at sites where scaffold was not present. Mineralisation measurement (AR stain) with BAG-S53P4 ( \pm PLGA) scaffolds without cells revealed some mineralisation as well, but this mineralisation only occurred at the site where the scaffold had been present. The results were consistent with a previous report suggesting that non-sintered BAG-S53P4 is capable of inducing osteogenic differentiation (Ojansivu et al., 2018; Ojansivu et al., 2015).

The exact cell biological mechanisms underlying the observed immunomodulatory and osteogenic 
properties of BAG-S53P4 scaffolds remain to be elucidated but are likely attributable to the dissolution of the BAG and the corresponding alkalinisation of the local environment and release of $\mathrm{Ca}, \mathrm{Si}$ and $\mathrm{P}$ species. For example, an alkaline environment affects macrophages by inhibiting the IL- $1 \beta$ response to several known inflammatory activators (Rajamäki et al., 2013) and increases osteoblast viability (Galow et al., 2017). Furthermore, extracellular Ca ions and Si species have been shown to have anti-inflammatory effects on murine macrophages (Huang et al., 2018) and to promote osteogenic differentiation of MSCs (Barradas et al., 2012; Lin et al., 2013). Additionally, elevated Ca-ion concentrations have been shown to enhance angiogenesis (Wu et al., 2009) with the Ca to Si ratio also playing a role in the angiogenic capacity (Li and Chang, 2013), thus warranting future research in the direct angiogenic capability of BAG-S53P4 ( \pm PLGA) scaffolds.

The alkalinisation of the local cell medium was observed in both macrophage and Rb-MSC media when incubated with BAG-S53P4 ( \pm PLGA) scaffolds. BAG-S53P4 showed significantly elevated pH compared with BAG-S53P4-PLGA and control cell media. In addition, both scaffolds demonstrated release of ion concentrations that were consistent with previous reports (Fagerlund et al., 2013). The difference in osteogenic induction between BAGS53P4 and BAG-S53P4-PLGA scaffolds may be partially explained by differences in their ionic dissolution patterns. Indeed, in this experimental setting, BAG-S53P4 scaffolds without a PLGA coating showed elevated $\mathrm{Si}$ and $\mathrm{Ca}$ concentrations in the ionic dissolution analysis, with PLGA coating probably acting as a mechanical barrier to hinder the actions of the BAG. Moreover, the lower values of $\mathrm{P}$ species in the ionic dissolution for BAG-S53P4 compared with BAG-S53P4-PLGA would support greater mineralisation/surface precipitation in the former group. This proposal is supported by SEM imaging, which revealed clear Ca-P reaction layers on the outer parts of the uncoated BAG particles of BAG-S53P4 scaffolds. This reactivity remained minimal at the surfaces of the polymer-coated BAG-S53P4-PLGA within the time frame studied.

These results demonstrated a proof of principle that the biological activity of BAG scaffolds could be modulated with the application of PLGA coating. The coating functioned not by directly inducing inflammation but by slowing down the BAG surface reactions and inhibiting the strong anti-inflammatory properties of the material. The delayed reactivity of the BAG-S53P4-PLGA scaffold may be beneficial for the formation of an IM and subsequent bone regeneration. This mechanism of action allows a period of initial inflammation followed by extended anti-inflammatory and osteogenic effects as the PLGA coating gradually degrades, revealing the surface of the BAG. Indeed, prior in vivo observations partially support this hypothesis (Björkenheim et al., 2017; Björkenheim et al., 2019). Of note, care must be taken when implementing novel bioactive materials into clinical practise. Regarding PLGA implants (e.g. interference screws), long term adverse effects have been documented - such as material fragmentation, incomplete degradation, adverse foreign body response, and cyst formation (Chevallier et al., 2019; Cox et al., 2014). However, these applications are different from the currently studied one and do not necessarily reflect the properties of the relatively thin PLGA coating.

\section{Conclusions}

Sintered BAG-S53P4 scaffolds demonstrated an immunomodulatory property on human macrophages that, as far as is known, has not been previously described. Furthermore, it was shown that sintered BAG-S53P4 scaffolds had direct osteogenic stimulatory effects on rabbit MSCs in vitro. These results were likely attributable to the alkalinisation of the surroundings and the release of the biologically active $\mathrm{Si}, \mathrm{Ca}$ and $\mathrm{P}$ species from the scaffold. These dynamics could be significantly modulated by application of a PLGA coating on the scaffold surface. Contrary to the initial hypothesis, the PLGA coating did not induce a stronger inflammatory response when compared to uncoated BAG. The result indicated that it served as a biodegradable barrier that attenuated BAG ion release and innate immunomodulatory and osteogenic effects. These results supported the role of coating BAG-S53P4 scaffolds with a biodegradable polymer, such as PLGA, to tune the immunomodulatory and osteogenic responses and consequently allow tailoring of the scaffold properties to meet the specific clinical need.

\section{References}

Allen RP, Bolandparvaz A, Ma JA, Manickam VA, Lewis JS (2018) Latent, immunosuppressive nature of poly(lactic-co-glycolic acid) microparticles. ACS Biomater Sci Eng 4: 900-918.

Arend WP, Malyak M, Guthridge CJ, Gabay C (1998) Interleukin-1 receptor antagonist: role in biology. Annu Rev Immunol 16: 27-55.

Baino F, Hamzehlou S, Kargozar S (2018) Bioactive glasses: where are we and where are we going? J Funct Biomater 9: 25. DOI: 10.3390/jfb9010025.

Banerjee C, McCabe LR, Choi JY, Hiebert SW, Stein JL, Stein GS, Lian JB (1997) Runt homology domain proteins in osteoblast differentiation: AML3/CBFA1 is a major component of a bone-specific complex. J Cell Biochem 66: 1-8.

Barnes GL, Kostenuik PJ, Gerstenfeld LC, Einhorn TA (1999) Growth factor regulation of fracture repair. J Bone Miner Res 14: 1805-1815.

Barradas AMC, Fernandes HAM, Groen N, Chai YC, Schrooten J, van de Peppel J, van Leeuwen JPTM, 
van Blitterswijk CA, de Boer J (2012) A calciuminduced signaling cascade leading to osteogenic differentiation of human bone marrow-derived mesenchymal stromal cells. Biomaterials 33: 32053215.

Björkenheim R, Strömberg G, Pajarinen J, Ainola M, Uppstu P, Hupa L, Böhling TO, Lindfors NC (2017) Polymer-coated bioactive glass S53P4 increases VEGF and TNF expression in an induced membrane model in vivo. J Mater Sci 52: 9055-9065.

Björkenheim R, Strömberg G, Ainola M, Uppstu P, Aalto-Setälä L, Hupa L, Pajarinen J, Lindfors NC (2019) Bone morphogenic protein expression and bone formation are induced by bioactive glass S53P4 scaffolds in vivo. J Biomed Mater Res B Appl Biomater 107: 847-857.

Chen QZ, Boccaccini AR (2006) Poly(D,L-lactic acid) coated 45S5 Bioglass-based scaffolds: processing and characterization. J Biomed Mater Res A 77: 445457.

Chevallier R, Klouche S, Gerometta A, Bohu Y, Herman S, Lefevre N (2019) Bioabsorbable screws, whatever the composition, can result in symptomatic intra-osseous tibial tunnel cysts after ACL reconstruction. Knee Surg Sports Traumatol Arthrosc 27: 76-85.

Ciraldo FE, Boccardi E, Melli V, Westhauser F, Boccaccini AR (2018) Tackling bioactive glass excessive in vitro bioreactivity: Preconditioning approaches for cell culture tests. Acta Biomater 75: 3-10.

Cox CL, Spindler KP, Leonard JP, Morris BJ, Dunn WR, Reinke EK (2014) Do newer-generation bioabsorbable screws become incorporated into bone at two years after ACL reconstruction with patellar tendon graft?: a cohort study. J Bone Joint Surg Am 96: 244-250.

Cyphert EL, Bil M, Recum von HA, Święszkowski W (2020) Repurposing biodegradable tissue engineering scaffolds for localized chemotherapeutic delivery. J Biomed Mater Res A 108: 1144-1158.

Day RM, Boccaccini AR (2005) Effect of particulate bioactive glasses on human macrophages and monocytes in vitro. J Biomed Mater Res A 73: 73-79.

Einhorn TA, Majeska RJ, Rush EB, Levine PM, Horowitz MC (1995) The expression of cytokine activity by fracture callus. J Bone Miner Res 10: 12721281.

Fagerlund S, Hupa L, Hupa M (2013) Dissolution patterns of biocompatible glasses in 2-amino-2hydroxymethyl-propane-1,3-diol (Tris) buffer. Acta Biomater 9: 5400-5410.

Fagerlund S, Massera J, Moritz N, Hupa L, Hupa M (2012) Phase composition and in vitro bioactivity of porous implants made of bioactive glass S53P4. Acta Biomater 8: 2331-2339.

Galow A-M, Rebl A, Koczan D, Bonk SM, Baumann W, Gimsa J (2017) Increased osteoblast viability at alkaline $\mathrm{pH}$ in vitro provides a new perspective on bone regeneration. Biochem Biophys Rep 10: 17-25.
Gerstenfeld LC, Cho TJ, Kon T, Aizawa T, Tsay A, Fitch J, Barnes GL, Graves DT, Einhorn TA (2003) Impaired fracture healing in the absence of TNF-alpha signaling: the role of TNF-alpha in endochondral cartilage resorption. J Bone Miner Res 18: 1584-1592.

Giannoudis PV, Einhorn TA, Marsh D (2007) Fracture healing: the diamond concept. Injury 38 Suppl 4: S3-S6.

Gruber HE, Ode G, Hoelscher G, Ingram J, Bethea S, Bosse MJ (2016) Osteogenic, stem cell and molecular characterisation of the human induced membrane from extremity bone defects. Bone Joint Res 5: 106-115.

Hench LL, Paschall HA (1973) Direct chemical bond of bioactive glass-ceramic materials to bone and muscle. J Biomed Mater Res 7: 25-42.

Hench LL, Polak JM, Xynos ID, Buttery LDK (2000) Bioactive materials to control cell cycle. Mater Res Innov 3: 313-323.

Hench LL, Xynos ID, Polak JM (2004) Bioactive glasses for in situ tissue regeneration. J Biomater Sci Polym Ed 15: 543-562.

Hoppe A, Güldal NS, Boccaccini AR (2011) A review of the biological response to ionic dissolution products from bioactive glasses and glass-ceramics. Biomaterials 32: 2757-2774.

Huang Y, Wu C, Zhang X, Chang J, Dai K (2018) Regulation of immune response by bioactive ions released from silicate bioceramics for bone regeneration. Acta Biomater 66: 81-92.

Jones JR (2013) Review of bioactive glass: from Hench to hybrids. Acta Biomater 9: 4457-4486.

Kankare J, Lindfors NC (2016) Reconstruction of vertebral bone defects using an expandable replacement device and bioactive glass S53P4 in the treatment of vertebral osteomyelitis: three patients and three pathogens. Scand J Surg 105: 248-253.

Kim T-H, Kang MS, Mandakhbayar N, El-Fiqi A, Kim H-W (2019) Anti-inflammatory actions of folatefunctionalized bioactive ion-releasing nanoparticles imply drug-free nanotherapy of inflamed tissues. Biomaterials 207: 23-38.

Lange J, Sapozhnikova A, Lu C, Hu D, Li X, Miclau T, Marcucio RS (2010) Action of IL-1beta during fracture healing. J Orthop Res 28: 778-784.

Leppäranta O, Vaahtio M, Peltola T, Zhang D, Hupa L, Hupa M, Ylänen H, Salonen JI, Viljanen MK, Eerola E (2008) Antibacterial effect of bioactive glasses on clinically important anaerobic bacteria in vitro. J Mater Sci Mater Med 19: 547-551.

Li H, Chang J (2013) Stimulation of proangiogenesis by calcium silicate bioactive ceramic. Acta Biomater 9: 5379-5389.

Lin K, Xia L, Li H, Jiang X, Pan H, Xu Y, Lu WW, Zhang Z, Chang J (2013) Enhanced osteoporotic bone regeneration by strontium-substituted calcium silicate bioactive ceramics. Biomaterials 34: 1002810042.

Lindfors NC, Hyvönen P, Nyyssönen M, Kirjavainen M, Kankare J, Gullichsen E, Salo J (2010a) 
Bioactive glass S53P4 as bone graft substitute in treatment of osteomyelitis. Bone 47: 212-218.

Lindfors NC, Heikkilä JT, Koski I, Mattila K, Aho AJ (2009) Bioactive glass and autogenous bone as bone graft substitutes in benign bone tumors. J Biomed Mater Res B Appl Biomater 90: 131-136.

Lindfors NC, Koski I, Heikkilä JT, Mattila K, Aho AJ (2010b) A prospective randomized 14-year follow-up study of bioactive glass and autogenous bone as bone graft substitutes in benign bone tumors. J Biomed Mater Res B Appl Biomater 94: 157-164.

Loi F, Córdova LA, Pajarinen J, Lin T-H, Yao Z, Goodman SB (2016) Inflammation, fracture and bone repair. Bone 86: 119-130.

Magri AMP, Fernandes KR, Assis L, Kido HW, Avanzi IR, Medeiros MDC, Granito RN, Braga FJC, Rennó ACM (2019) Incorporation of collagen and PLGA in bioactive glass: in vivo biological evaluation. Int J Biol Macromol 134: 869-881.

Mantsos T, Chatzistavrou X, Roether JA, Hupa L, Arstila H, Boccaccini AR (2009) Non-crystalline composite tissue engineering scaffolds using boroncontaining bioactive glass and poly(D,L-lactic acid) coatings. Biomed Mater 4: 055002. DOI: 10.1088/17486041/4/5/055002.

Masquelet AC, Fitoussi F, Begue T, Muller GP (2000) [Reconstruction of the long bones by the induced membrane and spongy autograft]. Ann Chir Plast Esthet 45: 346-353.

Munukka E, Leppäranta O, Korkeamäki M, Vaahtio M, Peltola T, Zhang D, Hupa L, Ylänen H, Salonen JI, Viljanen MK, Eerola E (2008) Bactericidal effects of bioactive glasses on clinically important aerobic bacteria. J Mater Sci Mater Med 19: 27-32.

Nicolete R, Santos dos DF, Faccioli LH (2011) The uptake of PLGA micro or nanoparticles by macrophages provokes distinct in vitro inflammatory response. Int Immunopharmacol. 11: 1557-1563.

Nurmi K, Kareinen I, Virkanen J, Rajamäki K, Kouri V-P, Vaali K, Levonen A-L, Fyhrquist N, Matikainen S, Kovanen PT, Eklund KK (2017) Hemin and cobalt protoporphyrin inhibit NLRP3 inflammasome activation by enhancing autophagy: a novel mechanism of inflammasome regulation. J Innate Immun 9: 65-82.

Ojansivu M, Hyväri L, Kellomäki M, Hupa L, Vanhatupa S, Miettinen S (2018) Bioactive glass induced osteogenic differentiation of human adipose stem cells is dependent on cell attachment mechanism and mitogen-activated protein kinases. Eur Cell Mater 35: 54-72.

Ojansivu M, Vanhatupa S, Björkvik L, Häkkänen H, Kellomäki M, Autio R, Ihalainen JA, Hupa L, Miettinen S (2015) Bioactive glass ions as strong enhancers of osteogenic differentiation in human adipose stem cells. Acta Biomater 21: 190-203.

Pelissier P, Masquelet AC, Bareille R, Pelissier SM, Amedee J (2004) Induced membranes secrete growth factors including vascular and osteoinductive factors and could stimulate bone regeneration. J Orthop Res 22: 73-79.
Rajamäki K, Nordström T, Nurmi K, Åkerman KEO, Kovanen PT, Öörni K, Eklund KK (2013) Extracellular acidosis is a novel danger signal alerting innate immunity via the NLRP3 inflammasome. J Biol Chem 288: 13410-13419.

Shi Q, Li ZY, Liverani L, Roether J, Chen Q, Boccaccini AR (2018) Positive effect of wrapping poly caprolactone/polyethylene glycol fibrous films on the mechanical properties of $45 S 5$ bioactive glass scaffolds. Int J Appl Ceram Technol 15: 921-929.

Stoor P, Söderling E, Salonen JI (1998) Antibacterial effects of a bioactive glass paste on oral microorganisms. Acta Odontol Scand 56: 161-165.

Stoor P, Pulkkinen J, Grénman R (2010) Bioactive glass S53P4 in the filling of cavities in the mastoid cell area in surgery for chronic otitis media. Ann Otol Rhinol Laryngol 119: 377-382.

Tan S-L, Ahmad TS, Selvaratnam L, Kamarul $\mathrm{T}$ (2013) Isolation, characterization and the multilineage differentiation potential of rabbit bone marrow-derived mesenchymal stem cells. J Anat 222: 437-450.

Tanaka K-I, Matsumoto E, Higashimaki Y, Katagiri T, Sugimoto T, Seino S, Kaji H (2012) Role of osteoglycin in the linkage between muscle and bone. J Biol Chem 287: 11616-11628.

Tanner MC, Heller R, Westhauser F, Miska M, Ferbert T, Fischer C, Gantz S, Schmidmaier G, Haubruck P (2018) Evaluation of the clinical effectiveness of bioactive glass (S53P4) in the treatment of non-unions of the tibia and femur: study protocol of a randomized controlled non-inferiority trial. Trials 19: 299. DOI: 10.1186/s13063-018-2681-9.

Varmette EA, Nowalk JR, Flick LM, Hall MM (2009) Abrogation of the inflammatory response in LPS-stimulated RAW 264.7 murine macrophages by Zn- and Cu-doped bioactive sol-gel glasses. J Biomed Mater Res A 90: 317-325.

Waddington RJ, Roberts HC, Sugars RV, Schönherr E (2003) Differential roles for small leucine-rich proteoglycans in bone formation. Eur Cell Mater 6: 12-21.

Waselau M, Patrikoski M, Juntunen M, Kujala K, Kääriäinen M, Kuokkanen H, Sándor GK, Vapaavuori O, Suuronen R, Mannerström B, Rechenberg von B, Miettinen S (2012) Effects of bioactive glass S53P4 or beta-tricalcium phosphate and bone morphogenetic protein-2 and bone morphogenetic protein-7 on osteogenic differentiation of human adipose stem cells. J Tissue Eng 3: 2041731412467789. DOI: 10.1177/2041731412467789.

Wilson J, Low SB (1992) Bioactive ceramics for periodontal treatment: comparative studies in the Patus monkey. J Appl Biomater 3: 123-129.

Wu Q, Shao H, Li J, Li J, Yang B, Webster KA, Yu H (2009) Extracellular calcium increases CXCR4 expression on bone marrow-derived cells and enhances pro-angiogenesis therapy. J Cell Mol Med 13: 3764-3773.

Xynos ID, Hukkanen MV, Batten JJ, Buttery LD, Hench LL, Polak JM (2000) Bioglass 45 S5 stimulates 
osteoblast turnover and enhances bone formation in vitro: implications and applications for bone tissue engineering. Calcif Tissue Int 67: 321-329.

Xynos ID, Edgar AJ, Buttery LDK, Hench LL, Polak JM (2001) Gene-expression profiling of human osteoblasts following treatment with the ionic products of Bioglass ${ }^{\circledR} 45 S 5$ dissolution. J Biomed Mater Res 55: 151-157.

Zhang D, Leppäranta O, Munukka E, Ylänen H, Viljanen MK, Eerola E, Hupa M, Hupa L (2010) Antibacterial effects and dissolution behavior of six bioactive glasses. J Biomed Mater Res A 93: 475-483.

Zomer HD, Roballo KC, Lessa TB, Bressan FF, Gonçalves NN, Meirelles FV, Trentin AG, Ambrósio CE (2018) Distinct features of rabbit and human adipose-derived mesenchymal stem cells: implications for biotechnology and translational research. Stem Cells Cloning 11: 43-54.

\section{Discussion with Reviewer}

Noel Davison: What was the rationale of using rabbit MSCs in this study?

Authors: The rabbit MSCs were chosen for practical reasons; they are commercially available, relatively low cost and simple to culture. Most importantly, however, they have been shown to be a reasonable model system for hMSCs (Zomer et al., 2018.) and have been used in studies in the field of biomaterial research (Guo et al., 2009, additional reference).

Noel Davison: There are a number of scaffold properties that may influence the inflammatory response; how might the authors identify the role of single or multiple parameters/properties (e.g. $\mathrm{pH}$, ion release, surface apatite formation) of the scaffolds described here might play in this?
Authors: The immunomodulatory effect of the BAG scaffolds are indeed multifaceted. Since the immunomodulatory effects were demonstrated in the current study in an indirect culture model, those must be attributable to release of soluble substances from the scaffold, rather than direct interaction of scaffold surface with the cells. Since the composition of the BAG is well characterised, the soluble immunomodulatory factors released from the scaffold must be various ions, elevation in the local pH or, possibly, some combination of these. For example, elevation of local $\mathrm{pH}$ has been shown to inhibit inflammasome activation and could also potentially inhibit other pro-inflammatory signalling pathways such as NF-kB (Rajamäki et al., 2013). Additionally, ions released from the scaffold (Ca, Si) have been shown to downregulate inflammation in macrophage cell cultures (Huang et al., 2018). A step-by-step analysis on how each of these factors alone, and in combination with other factors, could be conducted in simple macrophage cell culture model is needed. In addition, it would be useful to study the direct immunomodulatory effects of the scaffolds, macrophages and other cells that could be grown directly on the scaffold surfaces, before and after the layer of HA has been formed. These experiments are currently ongoing.

\section{Additional Reference}

Guo X, Park H, Liu G, Liu W, Cao Y, Tabata Y, Kasper FK, Mikos AG (2009) In vitro generation of an osteochondral construct using injectable hydrogel composites encapsulating rabbit marrow mesenchymal stem cells. Biomaterials 30: 2741-2752.

Editor's note: The Scientific Editor responsible for this paper was Joost de Bruijn. 